\title{
A Multi-regional Input-output Analysis of the Pollution Haven Hypothesis from the Perspective of Global Production Fragmentation Zengkai Zhang ${ }^{\text {a }}$, Kunfu Zhu ${ }^{* b}$; Geoffrey J. D. Hewings ${ }^{\mathrm{c}}$
}

\begin{abstract}
:
Pollution haven hypothesis is an important debate on the environmental effects of international trade, the pattern of which has been reshaped obviously by global production fragmentation recently. The production process is distributed globally, and the pollution haven effect of international trade is becoming more complicated. For instance, intermediate product trade corresponds to the largest share of embodied emissions, and the share of emissions induced by the global value chain related trade is increasing gradually. The aim of this paper is to make a comprehensive analysis on the pollution haven hypothesis in carbon emissions embodied in three different trade patterns from global, bilateral, and national perspectives. We propose a method to parcel the pollution haven hypothesis in a multi-regional input-output analysis and discuss the contribution of production fragmentation for global emissions. It is found that international production fragmentation generates global emissions savings. The intermediate product trade has a negative balance of avoided emissions. The final product trade becomes increasingly less environmentally effective during the period 1995-2009. There are significant differences in the environmental effects of different trade patterns for each country.
\end{abstract}

Keywords: pollution haven hypothesis; production fragmentation; input-output analysis JEL classification: C67; Q43; Q54; Q56 


\section{Introduction}

Low production cost and moderate environmental regulations of the developing countries are used to be the major incentive of developed counties to outsource the production process. Recently, there has been a growing awareness that the environmental problem is a global problem, the solution of which requires close global cooperation. The international climate agreement has developed from the stage of the United Nations Framework Convention on Climate Change in 1992 to the stage of the Kyoto Protocol in 1997 and the stage of the Paris Agreement in 2016. To address the problem of environmental externalities, environmental provisions are also becoming more and more visible in recent international trade agreements, such as the Trans-Pacific Partnership $\left(\mathrm{TPP}^{1}\right)$. An important debate on the environmental effects of international trade is the pollution haven hypothesis, which has become increasingly more complicated because global production fragmentation is reshaping the international trade pattern. The aim of this paper is to make a comprehensive analysis on the pollution haven hypothesis in carbon emissions embodied in three different trade patterns, from global, bilateral, and national perspectives.

Since the pollution haven hypothesis is first proposed by (e.g., Walter and Ugelow, 1979), researchers have devoted extensive effort to theoretical (e.g., Conrad, 2005; Kheder and Zugravu, 2008) and empirical study (e.g., Al-mulali and Tang, 2013; Eskeland and Harrison, 2003) on exploring and testing this hypothesis. Taylor (2005) notes that pollution haven hypothesis is at the center of the debate on the environmental effects of trade flows. The quantitative evaluation adopts different models, such as difference-in-differences model (Tang, 2015), simultaneous-equations model (He, 2006), gravity model of bilateral trade (Koźluk and Timiliotis, 2016), and other panel data estimation techniques (e.g., Cole and Elliott, 2005; Hoffmann et al., 2005; Levinson and Taylor, 2008; Rezza, 2013). Recently, there has been an increasing interest in adopting input-output models to analyze the environmental

\footnotetext{
${ }^{1}$ Sources: https://ustr.gov/trade-agreements/free-trade-agreements/trans-pacific-partnership/tpp-chapter-chapter -negotiating-5
} 
effects of trade (e.g., Dietzenbacher and Mukhopadhyay, 2007; López et al., 2013a; López et al., 2013b; López et al., 2013c; Su and Ang, 2014b; Su et al., 2013; Zhang et al., 2014). The research methodology of this study is based on input-output method.

This study builds on growing literature on the environmental effects of global production fragmentation with the development of global value chains (e.g., Dean and Lovely, 2010; Dietzenbacher et al., 2012; Jiang et al., 2015a; Jiang et al., 2015b; López et al., 2013a; Liu et al., 2016a; Meng et al., 2014; Pei et al., 2015; Su et al., 2013). Previous multi-regional input-output studies mainly focus on the source and destination of embodied emissions (e.g., Meng et al., 2014). However, policy makers may be more concerned about the environmental effects of a country's position in global value chains and about the environmental effects of bilateral trade with its direct upstream and downstream trade partners. With the development of global production fragmentation, countries specialize in different stages and connect with the world through different trade linkages. This study analyzes whether the participation of a country in global value chains generates an increase or decrease in global emissions on the basis of distinguishing three different trade patterns.

Arce González et al. (2012) and López et al. (2013c) isolate three trade patterns from the perspective of the international production stage and test the pollution haven hypothesis, respectively. The three patterns are trade in final goods, trade in intermediate goods for the last stage of production, and trade in intermediate goods for the remaining stages of international production. The first two trade patterns belong to the direct value added trade pattern proposed by Wang et al. (2017) or the traditional Ricardian trade proposed by Borin and Mancini (2015). The last trade pattern is just the narrowly defined global value chain related trade ${ }^{2}$ proposed by Wang et al. (2017). This present paper distinguishes different trade patterns in a similar way. The first two trade patterns are classified as the traditional trade patterns, and the last one is named the global value chain related trade patter. However, we enrich the literature by adopting another method proposed by Wang et al. (2017),

\footnotetext{
${ }^{2}$ For the global value chain related trade, the value added in intermediated products cross the borders at least twice.
} 
which decomposes the Leontief inverse matrix to distinguish the emissions induced by pure domestic and three different trade production activities. In addition, we introduce the Structural Decomposition Analysis (SDA) to assess the carbon transfer change over the period 1995-2009.

SDA is widely used to analyze carbon emissions embodied in international trade (Ang et al., 2016; Fan and Xia, 2012; Su and Ang, 2012; Su and Thomson, 2016; Xia et al., 2015; Xu and Dietzenbacher, 2014). There exists different decomposition approaches, such as the Dietzenbacher and Los (D\&L) approach (Dietzenbacher and Los, 1998), the two polar decomposition approach (Fan and Xia, 2012; Xia et al., 2015), the Logarithmic Mean Divisia Index (LMDI) method (e.g., Ang et al., 2003; Ang et al., 1998; Su and Thomson, 2016), and mean rate-of-change index approach (Chung and Rhee, 2001). Recent methodological developments mainly are the multiplicative SDA (Su and Ang, 2014a, 2015), and spatial SDA (Su and Ang, 2016). According to the guidelines on decomposition approach selection in SDA ( $\mathrm{Su}$ and Ang, 2012), this paper chooses the LMDI approach, which is an ideal decomposition method.

The previous studies evaluate the contribution of international trade to global emissions per unit of additional imports and exports (Dietzenbacher and Mukhopadhyay, 2007; Zhang, 2015) or by calculating the difference between the total emissions embodied in exports and total emissions avoided by imports (Arce González et al., 2012; Chen and Chen, 2011; Peters et al., 2007; Zhang et al., 2014). Both measures apply the domestic technology assumption and calculate the emissions that would have resulted from producing the imported products with domestic technology $y^{3}$. Two types of multi-region input-output analysis are the EEBT approach that considers total bilateral trade between regions and the MRIO approach that endogenously determines trade to intermediate consumption (Peters, 2008). The EEBT approach adopts the domestic technology assumption (e.g., Zhang et al., 2014)

\footnotetext{
${ }^{3}$ The technology assumption may also focus on the exports. For instance, Kander et al. (2015) focus on the emissions generated in the production of a country's exports, adopt the average carbon intensity for the relevant sector on the world market, and propose the technology-adjusted consumption-based accounting to reveal national abatement responsibility. This present paper focuses on the emissions avoided by a country's imports to reveal the effects of international trade on global emissions.
} 
in a similar way as the single regional input-output analysis (e.g., Su and Ang, 2013). However, there is no uniform approach to apply this assumption under the MRIO approach, which reflects international feedback (Su and Ang, 2011).

A typical way of applying the domestic technology assumption is by summing up and substituting the direct domestic and import requirements matrix (e.g., Lenzen et al., 2004; Serrano and Dietzenbacher, 2010; Tukker et al., 2013). Hertwich and Peter (2010) apply this assumption by replacing local and international input coefficients. López et al. (2013b) and López et al. (2013c) propose a method to parcel pollution haven hypothesis intro bi-regional input-output analysis and adopt the domestic technology assumption by substituting the domestic Leontief inverse matrix. López et al. (2013a) further extend the bi-regional case to the multi-regional case and adopt the domestic technology assumption by substituting the global Leontief inverse matrix. However, this present paper holds the viewpoint that the interregional input coefficients are not only determined by the production technology but also are closely related to the international trade pattern. To avoid the influence of the domestic technology assumption on the evaluation of the environmental effect of different trade patterns, this present paper only focuses on domestic emissions that are induced by exports through domestic economic linkage. In other words, this paper proposes another method to extend López et al.'s method (2013c) to the multi-regional case, both of which focus on the domestic Leontief inverse matrix. The main conclusions of this study are summarized as below.

First, this study decomposes the emissions associated with pure domestic economic activities and different trade patterns. The findings are as follows: traditional trade in intermediate products corresponds to the largest share of embodied emissions, the share of emissions induced by global value chains is increasing gradually, and the international net carbon transfer is mainly done through the final product trade. Second, this present study focuses on emissions that are induced by exports only through domestic economic linkage and proposes another method to parcel the pollution haven hypothesis into the multi-regional input-output analysis. We find that 
international production fragmentation generates global emissions savings, the intermediate product trade has a negative balance of avoided emissions, and the final product trade becomes increasingly less environmentally effective over the period 1995-2009. Third, this study provides a comprehensive analysis on the environmental effects of different trade patterns from the impacts on both national direct emissions and global emissions. The results show that the effects of different trade patterns on national and global emissions clearly vary according to each country's position in the global production network.

The reminder of the paper is organized into four sections. Section 2 introduces the calculation methodology. Section 3 presents the simulation results. The conclusions and policy implications follow in Section 4.

\section{Methodology}

Input-output analysis (Leontief, 1941) can be divided into the single-regional (e.g., Gavrilova and Vilu, 2012) and multi-regional (e.g., Wiedmann et al., 2010) input-output analysis. This present paper adopts the multi-regional input-output analysis framework that endogenously determines intermediate product trade among different regions. This section explains the methodology based on a world composed of $G$ countries and $N$ sectors. These countries are connected through the interregional trade of intermediate and final products, and each country's outputs are used to satisfy intermediate or final consumption. The multi-regional input-output analysis framework (Leontief, 1941) begins with an accounting balance of monetary flow.

$$
\left[\begin{array}{c}
X^{1} \\
X^{2} \\
\vdots \\
X^{g}
\end{array}\right]=\left[\begin{array}{cccc}
A^{11} & A^{12} & \cdots & A^{1 g} \\
A^{21} & A^{22} & \cdots & A^{2 g} \\
\vdots & \vdots & \ddots & \vdots \\
A^{g 1} & A^{g 2} & \cdots & A^{g g}
\end{array}\right]\left[\begin{array}{c}
X^{1} \\
X^{2} \\
\vdots \\
X^{g}
\end{array}\right]+\left[\begin{array}{c}
\sum_{r}^{G} Y^{1 r} \\
\sum_{r}^{G} Y^{2 r} \\
\vdots \\
\sum_{r}^{G} Y^{g r}
\end{array}\right]
$$

where $X^{s}$ represents the final output of country $s(s=1, \cdots, g), Y^{s r}$ represents the final demand of country $r(r=1, \cdots, g)$ for products from country $s, A^{s r}$ is the input coefficient matrix that represents the intermediate use in country $r$ of goods 
produced in country $s$. The elements of the input coefficient matrix satisfy $a_{i j}^{s r}=z_{i j}^{s r} / x_{j}^{r}$, where $z_{i j}^{s r}(i, j=1, \cdots, n)$ represents the transfer from sector $i$ of country $s$ to sector $j$ of country $r$. The intermediate input matrix from country $s$ to country $r$ is represented by $Z^{s r}=A^{s r} X^{r}$. Equation (1) can be rearranged as,

$$
\left[\begin{array}{c}
X^{1} \\
X^{2} \\
\vdots \\
X^{g}
\end{array}\right]=\left[\begin{array}{cccc}
I-A^{11} & -A^{12} & \cdots & -A^{1 g} \\
-A^{21} & I-A^{22} & \cdots & -A^{2 g} \\
\vdots & \vdots & \ddots & \vdots \\
-A^{g 1} & -A^{g 2} & \cdots & I-A^{g g}
\end{array}\right]^{-1}\left[\begin{array}{c}
\sum_{r}^{G} Y^{1 r} \\
\sum_{r}^{G} Y^{2 r} \\
\vdots \\
\sum_{r}^{G} Y^{g r}
\end{array}\right]=\left[\begin{array}{cccc}
B^{11} & B^{12} & \cdots & B^{1 g} \\
B^{21} & B^{22} & \cdots & B^{2 g} \\
\vdots & \vdots & \ddots & \vdots \\
B^{g 1} & B^{g 2} & \cdots & B^{g g}
\end{array}\right]\left[\begin{array}{c}
\sum_{r}^{G} Y^{1 r} \\
\sum_{r}^{G} Y^{2 r} \\
\vdots \\
\sum_{r}^{G} Y^{g r}
\end{array}\right]
$$

where $B^{s r}$, the Leontief inverse, represents the quantity of the gross output of country $s$ for a one-unit increase in the final demand of country $r$. From equation (2), the final output of country $r$ is as follows:

$$
X^{r}=\sum_{t}^{G} B^{r t} \sum_{u}^{G} Y^{t u}
$$

The intermediate input of country $r$ from country $s$ is $Z^{s r}=A^{s r} X^{r}$. The exports from country $s$ to country $r$ are $T^{s r}=Y^{s r}+A^{s r} X^{r}$. From Wang et al.'s study (2013), we can proof that $B^{r r}=L^{r r}+L^{r r} \sum_{t \neq r}^{G} A^{r t} B^{t r}$. From equation (3), we obtain:

$$
T^{s r}=Y_{T_{-} f^{s r}}^{Y^{s r}}+\underbrace{A^{s r} L^{r r} Y^{r r}}_{T_{-} i^{s r}}+\underbrace{A^{s r} L^{r r} \sum_{t \neq r}^{G} A^{r t} B^{t r} Y^{r r}+A^{s r} \sum_{t \neq r}^{G} B^{r t} Y^{t r}+A^{s r} \sum_{t}^{G} B^{r t} \sum_{u \neq r}^{G} Y^{t u}}_{T_{-} \mathrm{g}^{s r}}
$$

where $L^{r r}=\left(I-A^{r r}\right)^{-1}$ is the domestic Leontief inverse matrix of country $r$. $T_{-} f^{s r}$ defines trade in final products. The trade partner would directly absorb the exported products, and the exporter is located in the last stage of production. $T_{-} i^{s r}$ is the traditional trade in intermediate products for the last stage of international production, which need to be further processed by the trade partner before finally being absorbed by the trade partner. $T_{-} g^{s r}$ is the narrowly defined global value chain related trade (Wang et al., 2017). The traded products of the first two trade 
patterns cross the border once and are finally absorbed by the importer. The traded products of the global value chain related trade cross the border more than once and may be ultimately absorbed by the exporter, the importer or a third country.

Based on the balance of gross output $X^{s}=A^{s s} X^{s}+Y^{s s}+\sum_{s \neq r}^{M} T^{s r}$, we can decompose the gross output generated from each industry/country into different components:

$$
X^{s}=L^{s s} Y^{s s}+L^{s s} \sum_{s \neq r}^{G} T_{-} f^{s r}+L^{s s} \sum_{s \neq r}^{G} T_{-} i^{s r}+L^{s s} \sum_{s \neq r}^{G} T_{-} \mathrm{g}^{s r}
$$

The gross output of country $s$ is decomposed into four terms. The first term represents the output induced by the domestic final demand through the local industrial linkage, which has no relationship with the international production fragmentation. The other three terms represent the outputs induced by the final product trade, the traditional trade in intermediate products and the global value chain related trade (Arce González et al., 2012; López et al., 2013a; López et al., 2013c; Wang et al., 2017). We define the carbon intensity of the sector $i$ of country $s$ as $f_{i}^{s}=e_{i}^{s} / x_{i}^{s}$, where $e_{i}^{s}$ represents the carbon emissions of sector $i$ of country $s$. $F^{s}$ is a diagonal matrix composed of $f_{i}^{s}$. The emissions of country $s$ is

$$
E^{s}=F^{s} X^{s}=F^{s} L^{s s} Y^{s s}+F^{s} L^{s s} \sum_{s \neq r}^{G} T_{-} f^{s r}+F^{s} L^{s s} \sum_{s \neq r}^{G} T_{-} i^{s r}+F^{s} L^{s s} \sum_{s \neq r}^{G} T_{-} \mathrm{g}^{s r}
$$

The gross domestic emissions of country $s$ are decomposed into four terms ${ }^{4}$. The first term represents emissions that are induced by the domestic final demand through the local industrial linkage that has no relationship with the international production fragmentation. The other three terms represent the domestic emissions induced by the trade in final products, the traditional trade in intermediate products and the global value chain related trade. The decomposition is presented in figure 1.

\footnotetext{
${ }^{4} \mathrm{Su}$ and Ang (2011) propose the stepwise distribution of emissions embodied in trade (SWD-EET) method to trace the infinite distribution of embodied emissions in trade. If we decompose the global Leontief inverse matrix $\left(B^{s s}=L^{s s}+L^{s s} A^{s r} \sum_{r \neq s} B^{r s}\right.$ and $B^{s r}=L^{s s} \sum_{t \neq s} A^{s t} B^{t r}$ (Wang et al., 2013)) in an infinite process, Equation (6) will be aligning with the Equation (18) in Su and Ang's study (2011).
} 


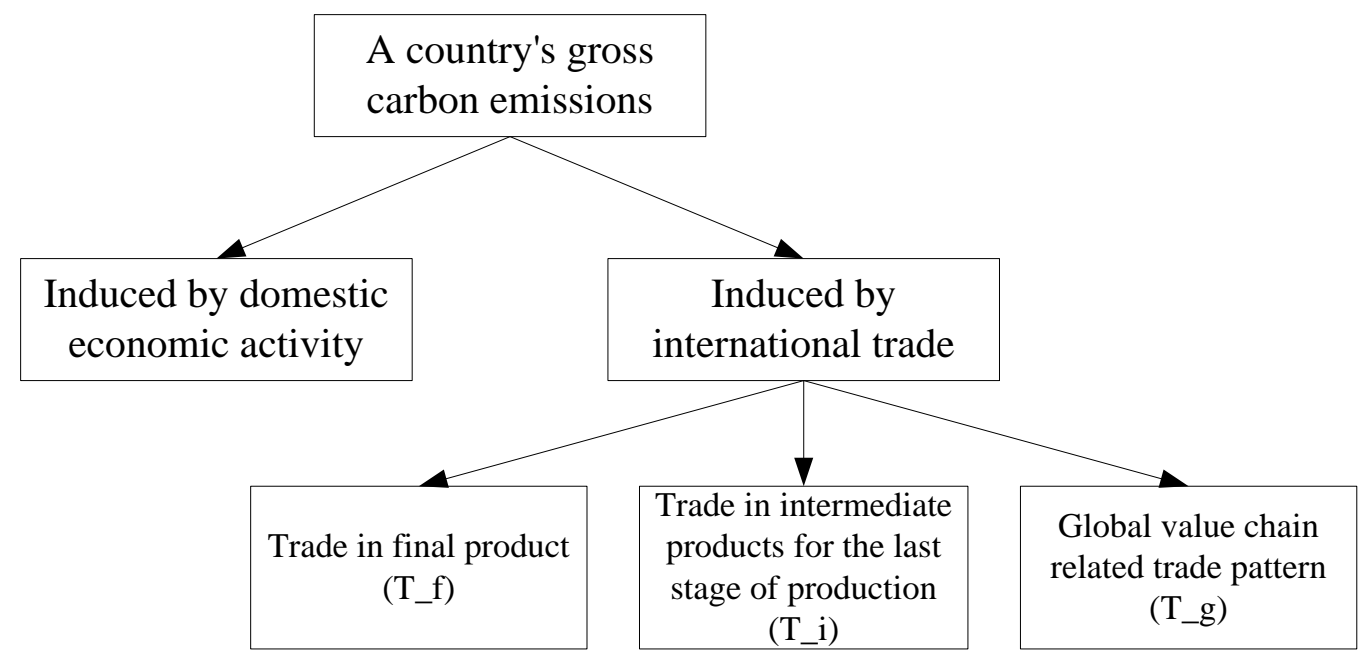

Figure 1. The decomposition of a country's gross emissions

The domestic emissions embodied in the exports from country $s$ to country $r$ is

$$
E E X^{s r}=F^{s} L^{s s} T^{s r}=F^{s} L^{s s} T_{-} f^{s r}+F^{s} L^{s s} T_{-} i^{s r}+F^{s} L^{s s} T_{-} \mathrm{g}^{s r}
$$

Equation (7) decomposes the domestic emissions embodied in gross exports from country $s$ to country $r$ into three terms by the trade pattern, the trade in final products, the traditional trade in intermediate products and the global value chain related trade. This present paper further introduces the Structural Decomposition Analysis (SDA) to clarify the driving forces of changes in carbon transfer through bilateral trade. According to the guidelines on decomposition approach selection in SDA (Su and Ang, 2012), this paper chooses the LMDI approach. In addition, this paper adopts the double deflation method to deflate the multi-regional input-output tables of 1995 and 2009 to the constant price. The changes of embodied emissions are decomposed into four sub-effects, shown as below.

$$
\begin{aligned}
\Delta E E X^{s r} & =E E X_{t l}^{s r}-E E X_{t 0}^{s r} \\
& =\Delta E E X_{F}^{s r}+\Delta E E X_{L}^{s r}+\Delta E E X_{T_{-} f}^{s r}+\Delta E E X_{T_{-} i}^{s r}+\Delta E E X_{T_{-} g}^{s r}
\end{aligned}
$$

where $\triangle E E X_{F}^{s r}$ is the carbon intensity effect, $\triangle E E X_{L}^{s r}$ is the production technology effect, $\Delta E E X_{T_{-} f}^{s r}$ is the final product trade effect, $\Delta E E X_{T_{-} i}^{s r}$ is the intermediate trade effect, $\triangle E E X_{T_{-} g}^{s r}$ is the global value chain related trade effect. The mathematical expression of each term is presented in Appendix C. The balance of the embodied emissions can be revealed as: 


$$
\begin{aligned}
B E E^{s r} & =E E X^{s r}-E E X^{r s} \\
& =\underbrace{\left(F^{s} L^{s s} T_{-} f^{s r}-F^{r} L^{r r} T_{-} f^{r s}\right)}_{(9-1)}+\underbrace{\left(F^{s} L^{s s} T_{-} i^{s r}-F^{r} L^{r r} T_{-} i^{r s}\right)}_{(9-2)} \\
& +\underbrace{\left(F^{s} L^{s s} T_{-} \mathrm{g}^{s r}-F^{r} L^{r r} T_{-} \mathrm{g}^{r s}\right)}_{(9-3)}
\end{aligned}
$$

Term (9-1) represents the balance of emissions embodied in traditional final product trade; term (9-2) represents the balance of emissions embodied in traditional intermediate product trade; and term (9-3) represents the balance of emissions embodied in global value chain related trade. $B E E^{s r}>0$ denotes the bilateral production fragmentation promotes the carbon emissions of country $s$; otherwise, the bilateral production fragmentation contributes to a decrease in the carbon emissions of country $s$. The effects of the position in the global production fragmentation on the carbon emissions of country $s$ is

$$
B E E^{s}=\sum_{r \neq s}^{G} E E X^{s r}-\sum_{r \neq s}^{G} E E X^{r s}
$$

$B E E^{s}>0$ means that the position in the global production fragmentation contributes to an increase in the carbon emissions of country $s . B E E^{s}<0$ means that the position in the global production fragmentation promotes a decrease in the carbon emissions of country $s$. Nevertheless, it is impossible to use $B E E$ to understand the influence of interregional trade on global emissions because the aggregation of $B E E$ for all countries is always zero $\left(\sum_{s}^{G} B E E^{s}=0\right)$.

The effects of production fragmentation on global emissions are evaluated by the difference between the emissions embodied in the exports and the emissions avoided by the imports (the balance of avoided emissions, BAE) (Dietzenbacher and Mukhopadhyay, 2007; López et al., 2013c). The emissions avoided by the imports of country $s$ from country $r$ is

$$
E A I^{s r}=F^{s} L^{s s} T^{r s}=F^{s} L^{s s} T_{-} f^{r s}+F^{s} L^{s s} T_{-} i^{r s}+F^{s} L^{s s} T_{-} \mathrm{g}^{r s}
$$

Equation (11) reflects the emissions of country $s$ that are avoided by imports from country $r$ through the trade in final products, the traditional trade in intermediate products, and the global value chain related trade. The balance of avoided emissions (BAE) is 


$$
\begin{aligned}
& B A E^{s r}=\left(E E X^{s r}-E A I^{s r}\right)+\left(E E X^{r s}-E A I^{r s}\right) \\
& =\underbrace{\left(F^{s} L^{s s}-F^{r} L^{r r}\right) T_{-} f^{s r}}_{(12-1-1)}+\underbrace{\left(F^{s} L^{s s}-F^{r} L^{r r}\right) T_{-} i^{s r}}_{(12-1)}+\underbrace{\left(F^{s} L^{s s}-F^{r} L^{r r}\right) T_{-} g^{s r}}_{(12-1-3)} \\
& +\underbrace{\left(F^{r} L^{r r}-F^{s} L^{s s}\right) T_{-} f^{r s}}_{(12-2-1)}+\underbrace{\left(F^{r} L^{r r}-F^{s} L^{s s}\right) T_{-} i^{r s}}_{(12-2)}+\underbrace{\left(F^{r} L^{r r}-F^{s} L^{s s}\right) T_{-} g^{r s}}_{(12-2-3)}
\end{aligned}
$$

Term (12-1) explains the PHH from the perspective of the production structure and carbon intensity of the exports from country $s$ to country $r$, which can be further divided into three trade patterns. Term (12-2) explains the PHH from the perspective of production structure and the carbon intensity of the imports of country $s$ from country $r$, which can also be further divided into three trade patterns. According to the modified calculation approach of PHH (Zhang et al., 2014), the contribution of the involvement of country $r$ in the global value chain on the global emissions is represented by:

$$
B A E^{s}=\left(\sum_{r \neq s}^{G} B A E^{s r}+\sum_{r \neq s}^{G} B A E^{r s}\right) / 2
$$

The expression of the gross balance of avoided emissions is presented below.

$$
B A E=\sum_{s}^{G} \sum_{r \neq s}^{G} B A E^{s r}
$$

A positive $B A E$ means the pollution haven hypothesis holds, and that a negative $B A E$ means that the interregional trade contributes to a decrease in gross emissions. Table 2 presents the meaning of different variables.

There exist different multi-regional input-output databases for this study. For instance, Owen (2015) makes comparison between three databased, the World Input-Output Database (WIOD), the Eora multi-region input-output table database, and the Global Trade Analysis Project (GTAP) database. WIOD uses the residence principle for emissions allocation, while the other two databases adopt territorial principle. Usubiaga and Acosta-Fernández (2015) strongly recommend the residence principle for emissions allocation. Therefore, this present paper adopts the WIOD database (Timmer et al., 2015). It should be pointed out that the WIOD database also has limitations. For example, Eora and GTAP have more detailed regional and sectoral classification than WIOD. The WIOD database covers 40 individual countries and a 
rest of world (ROW), which is made up of all countries not listed individually. The names of the countries are presented in Appendix A in the revised manuscript. The data quality of the individual countries is better than that of the ROW aggregate; therefore, this present paper mainly focuses on the environmental effects of the international trade between the individual countries. The key greenhouse gases (GHG) include carbon dioxide $\left(\mathrm{CO}_{2}\right)$, methane $\left(\mathrm{CH}_{4}\right)$, and nitrous oxide $\left(\mathrm{N}_{2} \mathrm{O}\right)$. This paper only discusses $\mathrm{CO}_{2}$, which accounts for the largest share to global greenhouse gas. The WIOD provides carbon emissions of 35 sectors (please refer to Appendix B) over the period 1995-2009.

\section{Results}

\subsection{Preliminary results on embodied emissions}

This section decomposes emissions associated with pure domestic economic activities and different trade patterns and presents the changing trends of emissions embodied in international trade.

\subsubsection{Regional comparisons of embodied emissions}

A country's direct carbon emissions are induced by pure domestic economic activities or are linked to international trade. The decomposition of emissions of the top ten economic agents in $2009^{5}$ is presented in Figure 2.

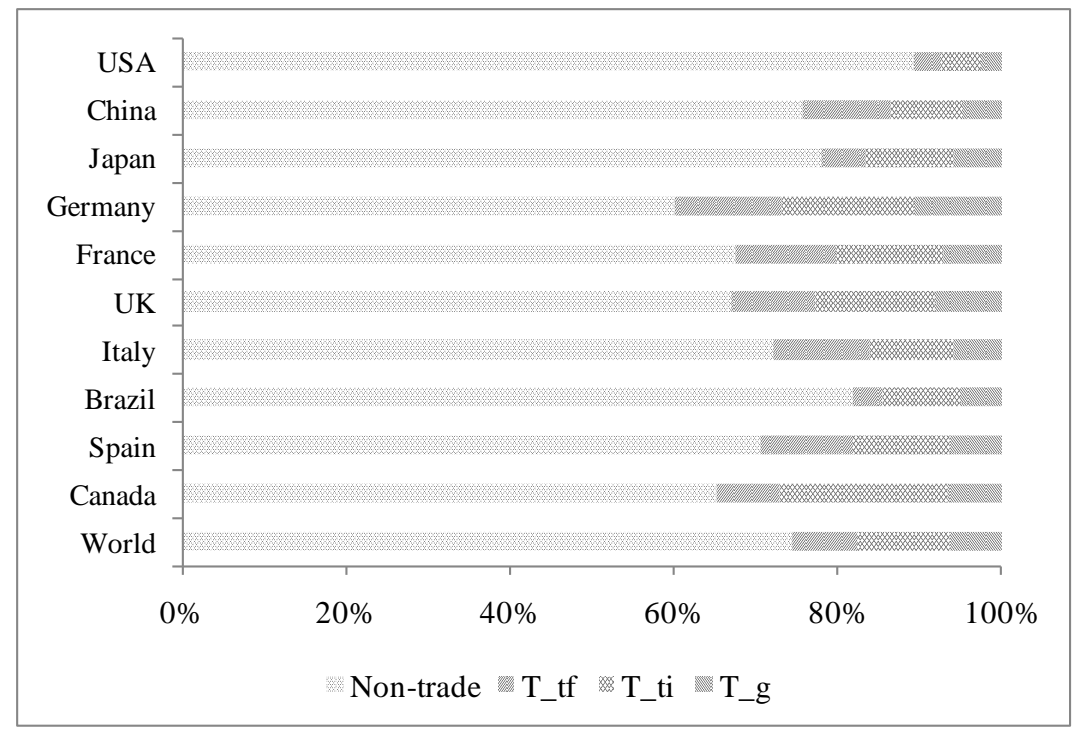

\footnotetext{
${ }^{5}$ Source: International Monetary Fund (IMF). World Economic Outlook Database, April 2010.
} 
Notes: Non-trade: pure domestic economic activities; T_f: trade in final products; $\mathrm{T}$ i: trade in intermediate products for the last stage of production; $\mathrm{T}$ _g: narrowly defined global value chain related trade.

Figure 2. Decomposition of direct emissions of the top ten economic agents and the global emissions in 2009

From the global perspective, about a quarter of the world's emissions are induced by international trade in 2009. The calculation result of this paper is smaller than the result (33\%) of Xu and Dietzenbacher's study (2014) because these two studies adopt different decomposition methods. Xu and Dietzenbacher (2014) analyze both direct and indirect emissions embodied in an individual country's exports of final and intermediate exports. This method will result in the double counting problem because a country's emissions embodied in intermediate exports can also be observed as the indirect emissions embodied in another country's exports of final products. To avoid the double counting problem, this present paper only focuses on domestic emissions that are induced by exports only through domestic economic linkage. More specifically, we find that $8 \%$ of global emissions are related to trade in final products, $11 \%$ corresponds to trade in intermediate goods for the last stage of production, and $6 \%$ is caused by the global value chain related trade.

Regional comparisons show that there are significant differences in the share of emissions induced by different economic activities for different countries. The consumption-oriented economic structure of the USA determines that direct emissions are mainly induced by domestic economic activity. The share of emissions induced by the exports of China is slightly lower than the world average level. The calculation results show that $24.34 \%$ of China's carbon emissions are induced by exports, being comparatively in consistent with the literature. For instance, Jiang et al. (2015a) find that $25.9 \%$ of China's carbon emissions are induced by nominal or processing exports. China has a greater share of emissions linked to trade in the final products because China specializes in international downstream production and exports large quantities of final products. The raw materials account for a larger share of the exports of Brazil. Therefore, the intermediate product trade corresponds to a greater share of emissions. Figure 2 also presents other countries' emissions induced by exports, and we will not discuss one by one. The impact of international trade on national direct emissions is usually evaluated by the difference between the emissions induced by exports and imports. This study further provides a more detailed discussion on the trade-related 
emissions for the top ten economy agents in 2009 .

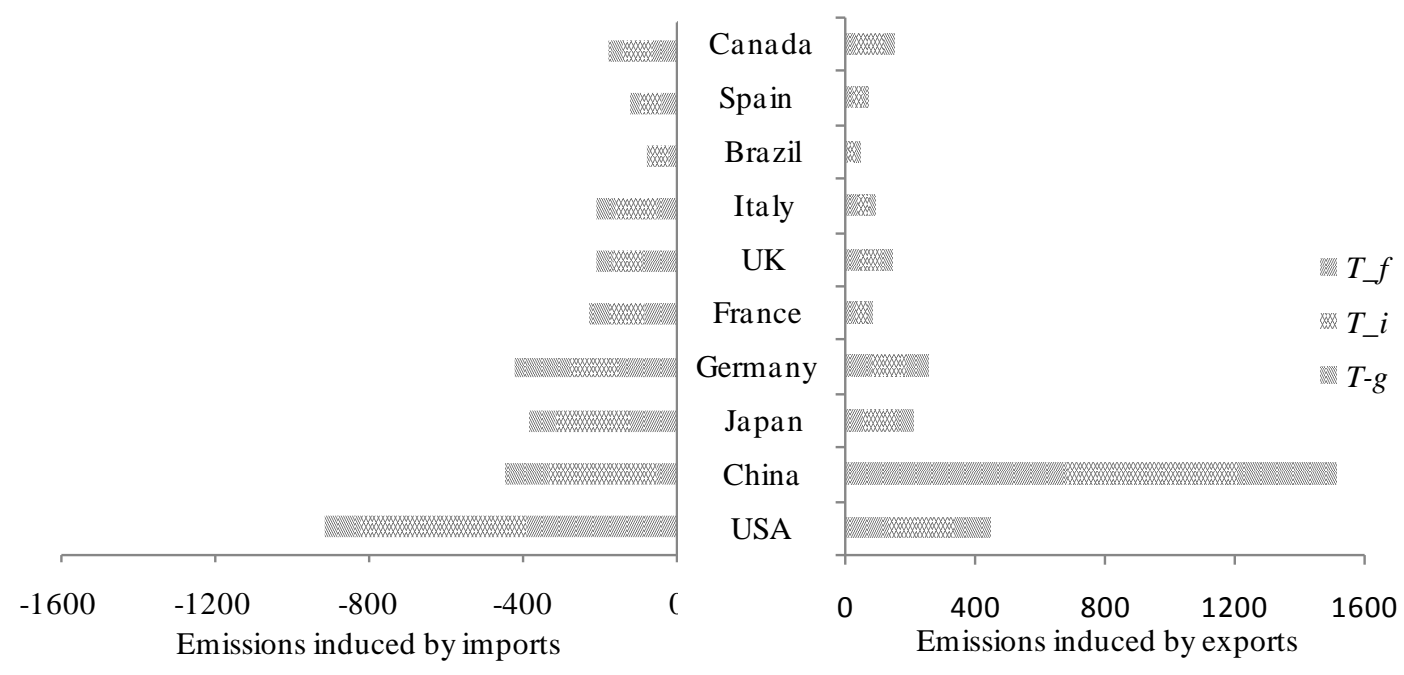

Figure 3. Emissions induced by trade of the top ten economy agents in 2009 (million tons)

Figure 3 presents the emissions induced by imports and exports of the top ten economies, which is decomposed into the emissions related to the three different trade patterns. The results show that imports of the USA corresponds to a greater volume of foreign emissions than the domestic emissions linked to exports. This means that the USA is a net carbon importer and generates emissions savings through international trade. Consistent with previous studies (e.g., Liu et al., 2016a), China is the largest net carbon exporter, and international trade promotes the direct carbon emissions of China. The other eight countries are all net carbon importers. The contribution of this study to the literature on international carbon transfer is that we provide a more in-depth analysis from the perspective of three different trade patterns. We can roughly classify the ten countries into three types by their net carbon transfer channels. The first type of net carbon transfer is mainly through the trade of final goods, which includes China, the USA, the United Kingdom, and Canada. The net carbon transfer of the second type is mainly through the trade in intermediated goods for the last stage of production, such as Japan, France, Italy, Brazil, and Spain. In addition, the global value chain related trade pattern plays the most significant role in net carbon transfer for Germany. This highlights that there are significant differences in the contributions of different trade patterns to the carbon transfers of different countries, which is closely related to a country's position in the international production network. For instance, international trade promotes China's direct emissions primarily through the trade in final goods, and the global value chain related trade pattern contributes less to 
the international carbon transfer. The net carbon transfer direction of a certain country may be different for different trade patterns. For example, the USA is an even net carbon exporter from the perspective of a global value chain related trade pattern, although the USA is net carbon importer from the perspective of total trade.

\subsubsection{Changing trends of embodied emissions}

The literature shows that emissions embodied in trade have increase obviously recently. For instance, Peters et al. (2011) use GTAP database and find that carbon emissions embodied in traded product increase from 4.3 billion tons in 1990 to 7.8 billion tons $\mathrm{CO} 2$ in 2008. The calculation results of this present paper show that carbon emissions embodied in trade increase from 4.1 billion tons in 1995 to 6.3 billion tons in 2009. This section further analyzes the changing trends of the share of emissions induced by different trade patterns. The calculation results are presented in Figure 4.

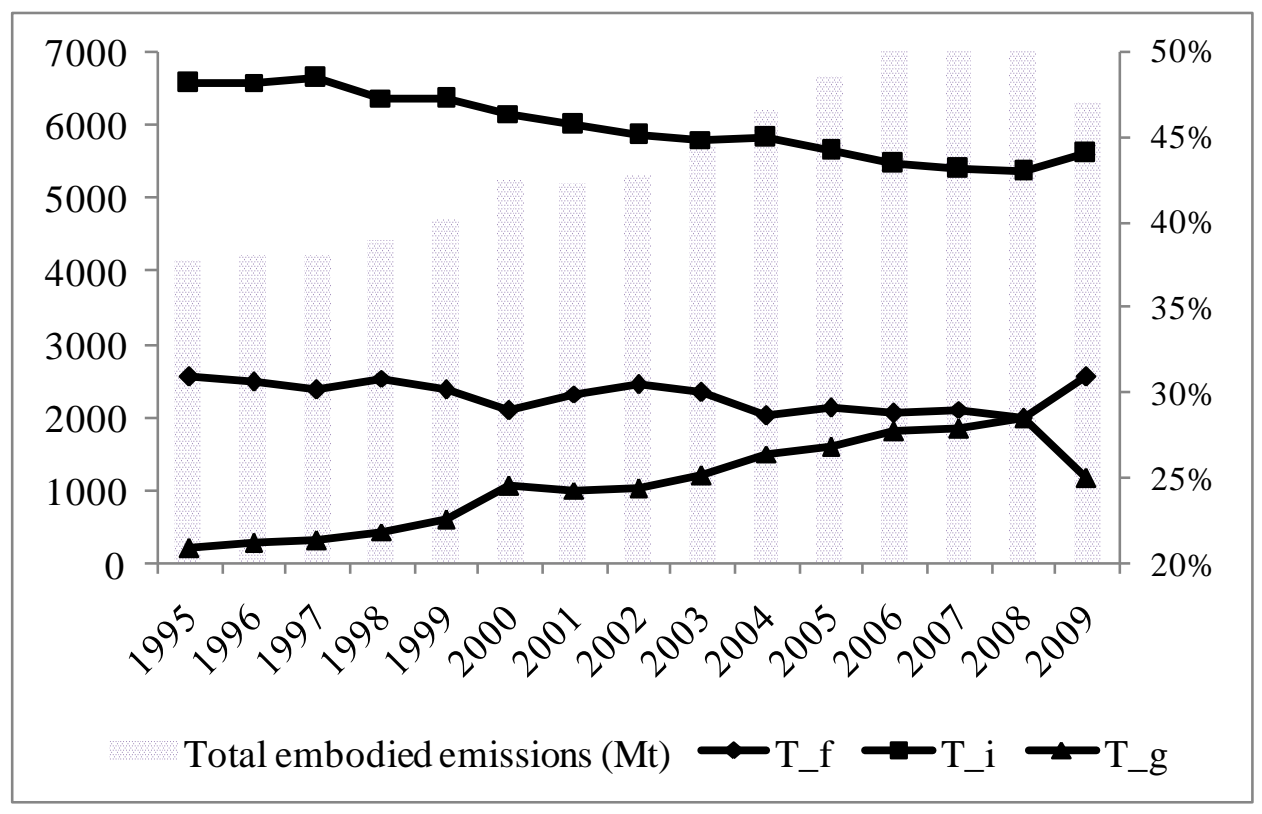

Figure 4. The structure of emissions induced by international trade

Figure 4 show that the trade in intermediate goods for the last production stage corresponds to the largest share of embodied emissions, which decreased from $48.18 \%$ in 1995 to the lowest point of $42.94 \%$ in 2008 , which further increased to $44.08 \%$ in 2009. The share of emissions induced by trade in the final product trade remains relatively stable. However, the share of emissions related to global value chains increased obviously and reached a peak in 2008. In 1995, only $20.85 \%$ of trade related emissions were induced by global value chains, while this number increased to 
$28.51 \%$ in 2008 . This reflects the quick development of global value chains over this period. The financial and economic crisis in 2008 shocked the international trade, especially the global value chain related trade. Therefore, the share of emissions corresponds to the global value chain related trade decreased in 2009, while the share of other two trade patterns increased obviously. In addition, the share of emissions induced by the trade in final products remained relatively stable over this period, which was approximately $30 \%$.

This paper discusses the changing trends of bilateral carbon transfer for 1995-2009, using the top two economy agents, China and the USA as examples. The carbon transfer between these two countries has attracted attentions from the literature. Shui and Harriss (2006) find that carbon emissions embodied in China's exports to the USA increase from 213 million tons in 1997 to 497 million tons in 2003. Guo et al. (2010) find that China's carbon emissions embodied in exports to USA have increased from 5\% to $7.76 \%$ of China's gross emissions over the period 2002-2006. Du et al. (2011) find that carbon emissions embodied in exports from China to the USA increase from 408.49 million tons in 2002 to 812.01 million tons in 2007. Zhao et al. (2016) discuss carbon transfer through final and intermediate trade between China and the USA. This present paper extends the literature by making a more detailed decomposition on carbon transfer through three different trade patterns. The calculation results are presented in Table 1.

Table 1. The net carbon transfer between China and USA for 1995-2009 (million tons)

\begin{tabular}{cccccccccc}
\hline & \multicolumn{3}{c}{\begin{tabular}{c} 
Emissions induced by \\
\multicolumn{2}{c}{ exports from China to USA }
\end{tabular}} & \multicolumn{2}{c}{ Emissions induced by } & \multicolumn{3}{c}{ Balance of emissions } \\
& imports & of China from USA & \multicolumn{2}{c}{ induced by China-USA trade } \\
\hline 1995 & 101.31 & 38.70 & 7.76 & 2.38 & 5.21 & 1.68 & 98.93 & 33.49 & 6.08 \\
1996 & 91.00 & 37.47 & 7.74 & 2.50 & 4.85 & 1.39 & 88.49 & 32.62 & 6.35 \\
1997 & 99.38 & 42.09 & 9.46 & 2.62 & 5.67 & 1.66 & 96.77 & 36.43 & 7.80 \\
1998 & 107.25 & 51.10 & 10.18 & 2.76 & 4.77 & 1.38 & 104.49 & 46.32 & 8.80 \\
1999 & 96.03 & 47.06 & 9.26 & 2.91 & 4.93 & 1.46 & 93.12 & 42.13 & 7.81 \\
2000 & 100.28 & 51.75 & 10.63 & 3.37 & 5.52 & 1.86 & 96.91 & 46.22 & 8.77 \\
2001 & 95.84 & 49.94 & 9.64 & 4.21 & 6.00 & 1.97 & 91.63 & 43.95 & 7.67 \\
2002 & 111.21 & 58.66 & 10.44 & 3.83 & 6.10 & 2.26 & 107.38 & 52.56 & 8.18 \\
2003 & 143.16 & 67.47 & 12.25 & 4.05 & 7.35 & 3.16 & 139.11 & 60.12 & 9.09 \\
2004 & 167.22 & 104.94 & 22.11 & 3.65 & 9.16 & 4.48 & 163.57 & 95.78 & 17.64 \\
2005 & 200.56 & 124.84 & 26.99 & 3.71 & 9.92 & 5.50 & 196.84 & 114.92 & 21.49 \\
2006 & 212.01 & 141.09 & 32.99 & 4.16 & 11.67 & 6.93 & 207.85 & 129.42 & 26.06
\end{tabular}




\begin{tabular}{cccccccccc}
\hline & \multicolumn{3}{c}{$\begin{array}{c}\text { Emissions induced by } \\
\text { exports from China to USA }\end{array}$} & \multicolumn{2}{c}{$\begin{array}{c}\text { Emissions induced by } \\
\text { imports of China from USA }\end{array}$} & \multicolumn{2}{c}{ Balance of emissions } \\
& induced by China-USA trade \\
\cline { 2 - 10 } & T_f & T_i & T_g & T_f & T_i & T_g & T_f & T_i & T_g \\
\hline 2007 & 217.48 & 136.86 & 34.11 & 5.09 & 15.82 & 9.52 & 212.40 & 121.04 & 24.60 \\
2008 & 194.12 & 134.31 & 35.13 & 6.03 & 19.31 & 10.29 & 188.09 & 115.00 & 24.84 \\
2009 & 178.77 & 114.62 & 25.90 & 6.01 & 19.74 & 7.62 & 172.76 & 94.87 & 18.28 \\
\hline
\end{tabular}

Table 1 shows that the emissions induced by exports from China to the USA are greater than those induced by imports, and the net carbon transfer direction is from China to the USA. The former is done mainly through the traditional final product trade, while the latter is done mainly through the traditional intermediate product trade. The carbon transfer between China and USA had three stages. For the first stage (before 2001), the bilateral carbon transfer between USA and China remained relatively stable. During this period, China experienced a sharp decrease in the carbon intensity associated with the Asian financial crisis that shocked the Chinese economy. In 2001, China became a member of the World Trade Organization (WTO), and the scale of international trade increased sharply, contributing to a rapid increase in the carbon transfer in the second stage (after 2001). For the third stage (2008-2009), the financial crisis resulted in decreased emissions induced by bilateral trade. From 1995 to 2009 , the embodied emissions transfer through the final product trade almost doubled, and the embodied emissions transfer through the intermediate product trade increased almost three times. This reflects the rapid development of global production fragmentation. This study further discusses the driving factors of emissions embodied in exports and imports of the top ten economic agents for 1995-2009 with a Structural Decomposition Analysis, the results are shown below.

Table 2. SDA results of emissions induced by national exports for 1995-2009

\begin{tabular}{lcccccc}
\hline & $\Delta \mathrm{EEX}_{\mathrm{F}}$ & $\Delta \mathrm{EEX}_{\mathrm{L}}$ & $\Delta E E X_{T_{-} f}$ & $\Delta E E X_{T_{-} i}$ & $\Delta E E X_{T_{-} g}$ & $\Delta \mathrm{EEE}$ \\
\hline USA & -80.02 & -165.45 & 81.96 & 75.68 & 67.14 & -20.69 \\
China & -1228.77 & 393.56 & 938.56 & 676.84 & 431.91 & 1212.09 \\
Japan & -2.83 & -8.63 & 31.36 & 38.93 & 38.45 & 97.28 \\
Germany & -112.62 & 11.72 & 71.57 & 74.79 & 57.65 & 103.12 \\
France & -71.04 & 3.19 & 24.96 & 15.72 & 15.28 & -11.90 \\
UK & -20.84 & -26.57 & 20.46 & 19.64 & 18.26 & 10.96 \\
Italy & -36.25 & -6.66 & 16.90 & 6.62 & 11.49 & -7.90 \\
Brazil & 37.24 & -5.51 & 3.30 & -2.34 & 1.86 & 34.55 \\
Spain & -23.58 & 9.46 & 17.34 & 14.84 & 10.83 & 28.89 \\
\hline & & & & & & 17
\end{tabular}




\begin{tabular}{ccccccc}
\hline & $\Delta \mathrm{EEX}_{\mathrm{F}}$ & $\Delta \mathrm{EEX}_{\mathrm{L}}$ & $\Delta E E X_{T_{-} f}$ & $\Delta E E X_{T_{-} i}$ & $\Delta E E X_{T_{-} g}$ & $\Delta \mathrm{EEE}$ \\
\hline Canada & -104.16 & 0.08 & 27.22 & 50.97 & 23.95 & -1.94 \\
\hline
\end{tabular}

Table 2 presents the structural decomposition analysis results for the emissions embodied in exports of the top ten economies for the period between 1995 and 2009. The change in embodied emissions ( $\triangle \mathrm{EEE}$ ) is explained from the perspectives of carbon intensity $\left(\Delta \mathrm{EEX}_{\mathrm{F}}\right)$, production technology $\left(\Delta \mathrm{EEX}_{\mathrm{L}}\right)$, and trade scale of the three different patterns $\left(\Delta E E X_{T_{-} f}, \Delta E E X_{T_{-} i}\right.$ and $\left.\Delta E E X_{T_{-} g}\right)$. The results show that China faces the largest increase in emissions embodied in exports, which is mainly determined by the changes in production technology and trade scale. Some countries face a decrease in emissions that is embodied in exports over this period, such as the USA. The main contributor is the change in carbon intensity and production technology. This can be explained by clean technology development. The production technology change also contributes to an increase in embodied emissions for Germany, France, Spain and Canada. Xu and Dietzenbacher (2014) explain this based on the increase in the share of intermediate inputs per unit of outputs. The changes in the trade scale of different patterns all contribute to an increase in emissions embodied in exports, except Brazil. However, different trade patterns play different roles in promoting embodied emissions for different countries. For instance, the increase in emissions embodied in China's exports mainly resulted from the trade in final products, while the trade in intermediate products contributes the most to the increase of emissions embodied in the exports of Canada. In addition, global value chain related trade also plays an important role in the changing trends of embodied emissions, such as Japan.

\subsection{Environmental effects of different trade patterns}

With the balance of avoided emissions, this section tests the pollution haven hypothesis from the global, bilateral and national perspectives.

\subsubsection{Global perspective}

We first evaluate the contribution of international production fragmentation to global emissions through different trade patterns. The calculation results are shown below. 


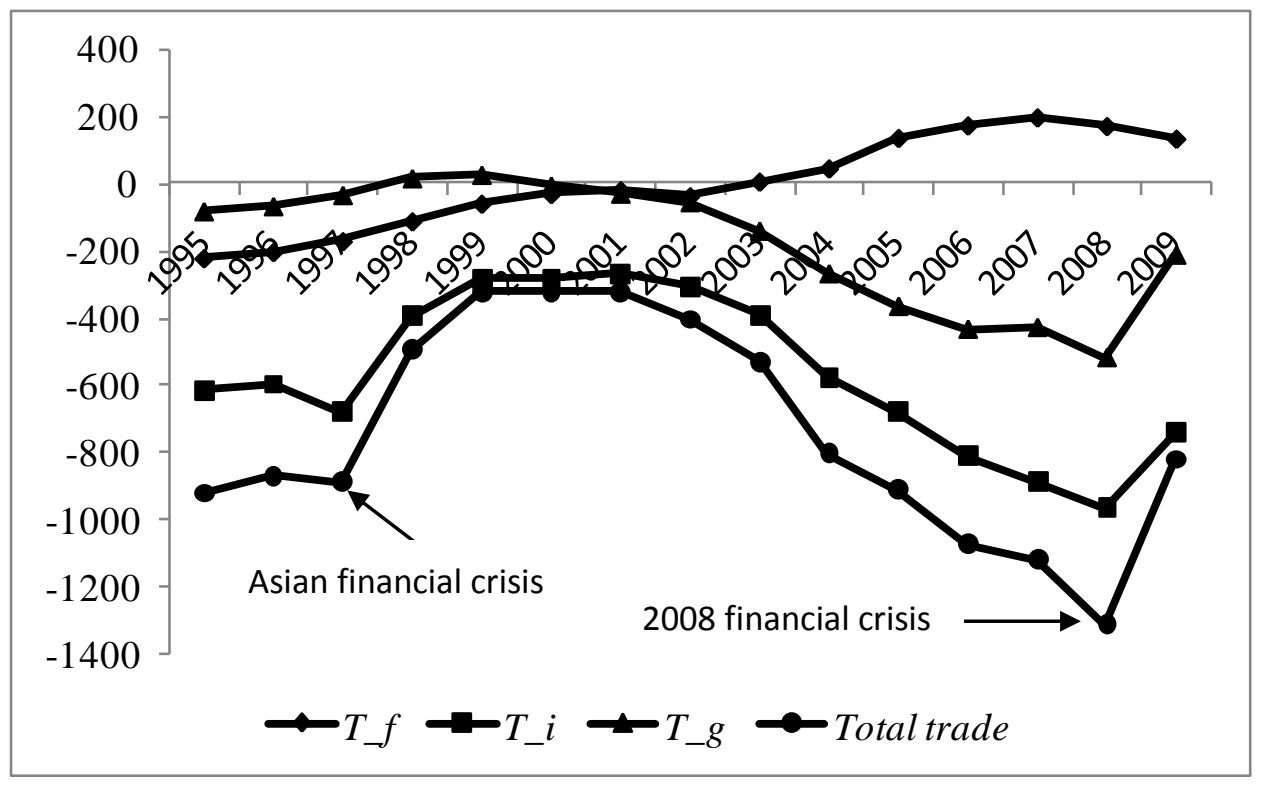

Figure 5. The effects of three different trade patterns on global emissions (million tons)

Figure 5 presents the changing trend in the balance of avoided emissions through international trade over the period 1995-2009, and the trade is decomposed into three different trade patterns. The results show that total international trade corresponds to a negative balance of avoided emissions. This means that international trade contributes to a decrease in global emissions, and the pollution haven hypothesis does not hold. For instance, in the absence of international trade, global carbon emissions would increase by 822.61 million tons in 2009. The conclusion is similar to that of López et al.' study (2013a) (1101.11 million tons in 2009). Both of this present paper and López et al.' study (2013a) adopt the WIOD database and test the pollution haven hypothesis by balance of avoided emissions. The results of these two studies are different. First, these two studies adopt different approaches to adopt the domestic technology assumption. López et al.' study (2013a) substitute the global Leontief inverse matrix. However, this present paper subsitute the domestic Leontief inverse matrix. Second, these two studies adopt different regional aggregation level. López et al.' study (2013a) (7 regions) adopts a relatively smaller regional aggregation level than this present paper (41 regions).

Figure 5 shows that the pollution haven hypothesis is obviously influenced by the Asian financial crisis in 1997 and the financial crisis in 2008, and the balance of avoided emissions clearly increased after 1997 and 2008. First, the governments adopt 
economic stimulus measures after the financial crisis shock and pay less attention to environment protection. Therefore, international trade generates less carbon savings. Second, the developing countries enjoy faster economic recovery than the developed countries. For instance, China's economic growth rate reaches as high as $9.2 \%$ in $2009^{6}$. The developing countries correspond to greater carbon intensity, which result in a greater balance of avoided emissions. In addition, Figure 5 provides a more detailed information on the pollution haven hypothesis from the perspective of three different trade patterns. The BAE of trade in the final products changes from negative to positive during this period. This reflects that the last stage of the global production chain gradually concentrates on the countries with relatively higher carbon intensity and contributes to an increase in global emissions. The trade in intermediate products for the last stage of production contributes to the largest decrease in global emissions and is also influenced obviously by the Asian financial crisis and the global financial crisis in 2008. The impact of global value chain related trade on global emissions is not obvious before 2002 and contributes to the growing emissions savings after 2002 . The BAE of this trade pattern was more clearly influenced by the global financial crisis in 2008 compared to the Asian financial crisis in 1997 because the former has broader influence.

\subsubsection{Bilateral perspective}

International trade can be observed as a collection of bilateral trade flows. To provide a more detailed discussion on the environmental effects of international trade, this section further discusses the pollution haven effect of international trade from the bilateral perspectives. The literature on environmental effects of international trade is also tend to discuss from the bilateral perspective (e.g., Ackerman et al., 2007; Guo et al., 2010; Tan et al., 2013; Zhang et al., 2014). This present paper attempts to extend the literature by clarifying whether the international carbon flow generates an increase or decrease in global emissions from the perspective of three different trade patterns. Here, we list the environmental effect of the top ten net carbon flows of the three different trade patterns.

\footnotetext{
${ }^{6}$ Data sources: www.stats.gov.cn
} 
Table 3. The environmental effect of the top ten net carbon flow (million tons)

\begin{tabular}{|c|c|c|c|c|c|c|c|c|c|}
\hline & \multicolumn{3}{|c|}{ Trade in final products } & \multicolumn{3}{|c|}{$\begin{array}{l}\text { Trade in intermediate products for the } \\
\text { last stage of production }\end{array}$} & \multicolumn{3}{|c|}{$\begin{array}{l}\text { Narrowly defined global value chain } \\
\text { related trade }\end{array}$} \\
\hline & Bilateral trade & Net transfer & BAE & Bilateral trade & Net transfer & BAE & Bilateral trade & Net transfer & BAE \\
\hline 1 & China-USA* & 172.76 & 116.10 & China-USA & 94.87 & 42.35 & China-Germany & 22.08 & 6.93 \\
\hline 2 & China-Japan & 60.44 & 21.21 & China-Japan & 31.91 & -30.42 & China-Korea & 21.84 & -6.03 \\
\hline 3 & China-Germany & 40.09 & -0.23 & Canada-USA & 27.08 & 2.81 & China-USA & 18.28 & -0.39 \\
\hline 4 & India-USA & 24.72 & 11.27 & Russia-Italy & 25.88 & 19.57 & Russia-Germany & 15.99 & 9.69 \\
\hline 5 & China-Canada & 22.85 & 16.09 & Taiwan-China & 18.33 & -30.08 & China-Japan & 13.24 & -16.63 \\
\hline 6 & China-UK & 21.49 & 13.55 & Russia-China & 17.40 & -6.91 & China-Mexico & 12.10 & 8.69 \\
\hline 7 & China-Australia & 20.70 & 12.90 & China-Germany & 13.95 & -19.92 & Russia-Netherlands & 11.76 & 9.69 \\
\hline 8 & China-France & 20.36 & 12.08 & Russia-USA & 13.37 & 8.07 & Russia-Italy & 10.75 & 8.53 \\
\hline 9 & China-Russia & 19.05 & -2.64 & China-India & 12.63 & 2.03 & China-Netherlands & 7.58 & 4.01 \\
\hline 10 & China-India & 18.12 & 1.58 & Russia-France & 11.81 & 6.52 & Russia-China & 7.47 & 1.33 \\
\hline
\end{tabular}

*Notes, we list the two countries of bilateral trade by the origin and destination of net carbon transfer. For instance "China-USA" means the net carbon transfer direction is from China to USA.

Although the emissions induced by the trade in intermediate products have the largest share (see section 3.2), table 3 shows that the bilateral net carbon transfer is mainly done through the traditional final product trade. The downstream production process is sensitive to the labor cost and is mainly centered in developing countries. As the world's factory, China is the largest net carbon exporter in 2009, predominantly induced by the final product exports to developed countries such as the USA, Japan, and Germany. In addition, China's significant carbon intensity and large trade surplus also contributes to carbon leakage from developed countries to China through international trade. From the perspective of trade in intermediate products for the last stage of production, the main sources of net carbon transfer are China, Canada, Russia and Taiwan. For instance, raw materials from Russia mainly support production in European countries. The greatest net carbon flow via the global value chain related trade is from China to Germany. However, the contribution of global value chain related trade to the international carbon transfer is relatively smaller than the other two trade patterns. This highlights that the effect of the development of global value chains on international carbon leakage is limited, which is mainly done through the trade in final products. We further test the pollution haven hypothesis of different trade flows.

The results show that trade in final products generally corresponds to a positive balance of avoided emissions except between China and Germany and between China 
and Russia. For instance, the bilateral trade in final products between China and the USA raises global emissions by 116.10 million tons. From the perspective of trade in intermediate products for the last stage of production, the bilateral trade that contributes the most to global emissions is the trade flow between China and the USA (BAE is 42.35 million tons), followed by that between Russia and Italy (BAE is 19.57 million tons). At the same time, the bilateral trade of China-Japan (BAE is -30.42 million tons), Taiwan-China (BAE is -30.08 million tons), and China-Germany (BAE is -19.92 million tons) corresponds to negative BAE. This means that the intermediate product trade between these two countries generates global emissions savings. From the perspective of the global value chain related trade pattern, the absolute size of the BAE is relatively smaller than the other two trade patterns. This further indicates that the effect of the development of global value chains on global emissions is not obvious.

Table 3 also presents the pollution haven effect of bilateral trade. For instance, the China-USA bilateral trade raises global emissions by 267.24 million tons. From the perspectives of different trade patterns, the BAE for the bilateral trade in final products is 116.10 million tons, the BAE for trade in intermediate products for the last stage of production is 42.35 million tons, and the BAE for the narrowly defined global value chain related trade is -0.39 million tons. Guo et al. (2010) find that bilateral trade between China and the USA increase global emissions by 385.32 million tons in 2005. The positive BAE for the China-USA bilateral trade can be explained from the China's trade surplus with the USA, which has relatively lower carbon intensity. Germany also has a trade deficit with China, but the size of trade deficit is smaller than the USA. In addition, China imports large scale of industrial products from Germany, which has relatively lower carbon intensity. Therefore, the bilateral trade between China and Germany generates global emissions savings. The calculation results show that bilateral trade in intermediate products for the last stage of production contributes most to the reduction in global emissions. However, the narrowly defined global value chain related trade corresponds to positive BAE.

Table 3 only presents the pollution haven effect of the top ten net carbon flows. This study will not discuss the pollution haven effect of different bilateral trade flows one by one. In addition, readers can also obtain the pollution haven effects of bilateral trade that are not listed here. For instance, Tan et al. (2013) find that China-Australia 
bilateral trade causes a reduction in global emissions in 2010 because Australia has relatively lower carbon intensity for the exported products. This study finds that China-Australia trade contributes to a reduction (-30.91 million tons) in global emissions in 2009. The BAE for trade in final products is 12.90 million tons, the BAE for trade in intermediate products for the last stage of production is -29.27 million tons, and the BAE for the narrowly defined global value chain related trade is -14.54 million tons. This highlights that China-Australia trade reduces global emissions mainly through the international trade in intermediate products.

\subsubsection{National perspective}

Different countries specialize in different stages of international production. This section evaluates the environmental effect of each country's trade linkages with the world from the perspectives of the balance of embodied emissions and the balance of avoided emissions.

Table 4. Environmental effects of different trade patterns of each country in 2009 (million tons)

\begin{tabular}{lcccccccc}
\hline \multirow{2}{*}{ Countries } & \multicolumn{4}{c}{ BEE } & \multicolumn{5}{c}{ BAE } \\
\cline { 2 - 8 } & T_f & T_i & T_g & T_total & T_f & T_i & T_g & T_total \\
\hline Australia & -33.15 & -9.63 & 4.00 & -38.78 & 6.05 & -35.18 & -23.44 & -52.57 \\
Austria & -11.62 & -9.73 & -13.21 & -34.56 & -1.77 & -3.87 & 1.27 & -4.38 \\
Belgium & -12.63 & -4.73 & -38.14 & -55.51 & -1.00 & -8.72 & 6.18 & -3.53 \\
Bulgaria & 3.66 & 2.39 & 0.18 & 6.22 & -0.95 & 0.70 & 1.51 & 1.26 \\
Brazil & -14.68 & -22.70 & 2.99 & -34.39 & 2.85 & -3.25 & -4.57 & -4.96 \\
Canada & -34.75 & 18.20 & -11.23 & -27.78 & 9.38 & -0.81 & 1.84 & 10.41 \\
China & 625.10 & 250.23 & 187.42 & 1062.75 & 140.88 & -104.77 & -21.10 & 15.00 \\
Cyprus & -0.82 & -1.28 & -0.45 & -2.55 & -0.81 & -0.37 & -0.01 & -1.18 \\
Czech Republic & 2.41 & 4.41 & -6.42 & 0.40 & -1.28 & -0.73 & 2.34 & 0.33 \\
Germany & -71.29 & -20.63 & -76.81 & -168.73 & -26.33 & -55.55 & 0.58 & -81.30 \\
Denmark & 3.07 & 17.20 & -4.32 & 15.95 & -5.60 & -11.47 & 0.36 & -16.72 \\
Spain & -17.44 & -26.27 & -12.91 & -56.62 & 1.48 & -1.19 & 1.04 & 1.33 \\
Estonia & 1.07 & 1.30 & 0.25 & 2.63 & -0.74 & -0.92 & -0.67 & -2.33 \\
Finland & -3.20 & -4.22 & -7.23 & -14.65 & -2.13 & -1.76 & 2.38 & -1.51 \\
France & -50.75 & -55.81 & -36.78 & -143.33 & -4.38 & -10.00 & 0.36 & -14.02 \\
United Kingdom & -47.21 & -17.55 & -8.84 & -73.60 & -3.60 & -3.68 & 2.87 & -4.40 \\
Greece & -7.55 & -12.93 & -1.74 & -22.22 & -5.78 & -21.86 & -8.52 & -36.17 \\
Hungary & -1.26 & -1.66 & -8.90 & -11.82 & -1.75 & -0.38 & 2.34 & 0.22 \\
Indonesia & 0.78 & 3.79 & 12.31 & 16.88 & 4.89 & -14.64 & -8.99 & -18.74 \\
India & 42.65 & -6.00 & 6.12 & 42.77 & 30.23 & -48.59 & 3.83 & -14.54 \\
Ireland & -6.24 & -5.52 & -15.15 & -26.91 & -6.00 & -6.84 & 1.20 & -11.64 \\
Italy & -14.59 & -70.11 & -30.88 & -115.58 & -12.04 & 8.46 & 5.23 & 1.64 \\
& & & & & & & 23 &
\end{tabular}




\begin{tabular}{lcccccccc}
\hline \multirow{2}{*}{ Countries } & \multicolumn{3}{c}{ BEE } & \multicolumn{3}{c}{ BAE } \\
\cline { 2 - 9 } Japan & T_f & T_i & T_g & T_total & T_f & T_i & T_g & T_total \\
Korea & -70.20 & -87.02 & -15.17 & -172.39 & 9.24 & -52.68 & -22.41 & -65.85 \\
Lithuania & 26.58 & 31.56 & -44.01 & 14.12 & -2.57 & -71.69 & -64.66 & -138.92 \\
Luxembourg & -2.23 & -1.69 & -4.32 & -8.24 & 0.06 & 0.06 & 1.41 & 1.53 \\
Latvia & -1.23 & -0.28 & -4.02 & -5.53 & -0.78 & -3.59 & 0.21 & -4.16 \\
Mexico & -0.84 & -0.86 & -0.76 & -2.46 & 0.00 & 0.20 & 0.30 & 0.49 \\
Malta & -8.12 & -4.00 & -19.25 & -31.37 & 2.93 & 0.99 & 4.38 & 8.30 \\
Netherlands & -0.35 & -0.06 & -0.37 & -0.78 & -0.19 & -0.36 & -0.24 & -0.79 \\
Poland & -3.29 & 1.59 & -39.55 & -41.24 & -1.94 & -6.59 & 10.88 & 2.36 \\
Portugal & 14.91 & 4.32 & 2.19 & 21.41 & 0.11 & -0.69 & 1.58 & 1.01 \\
Romania & -1.93 & -2.57 & -1.66 & -6.16 & -1.03 & -1.08 & -0.18 & -2.29 \\
Russia & 0.22 & -2.97 & 1.09 & -1.66 & -0.49 & -0.50 & 0.40 & -0.59 \\
Slovak Republic & -17.50 & 223.80 & 193.23 & 399.53 & -48.58 & 44.25 & 57.52 & 53.19 \\
Slovenia & -1.55 & -0.94 & -4.71 & -7.20 & -0.79 & 1.02 & 2.50 & 2.74 \\
Sweden & -1.22 & -0.32 & -2.29 & -3.83 & -0.95 & -0.27 & 0.59 & -0.63 \\
Turkey & -10.09 & -5.04 & -17.12 & -32.25 & -3.63 & -9.01 & 0.81 & -11.82 \\
Taiwan & -11.51 & -0.93 & -0.60 & -13.03 & 3.82 & 0.24 & 1.78 & 5.84 \\
United states & 12.86 & 52.24 & -6.08 & 59.03 & 3.01 & -39.14 & -52.49 & -88.62 \\
Rest of world & -255.10 & -229.74 & 15.61 & -469.23 & 59.71 & 14.12 & -3.71 & 70.13 \\
\hline
\end{tabular}

Table 4 presents the environmental effect of each country's gross international trade activity. The BEE show the impact of international trade on each country's direct emissions, and the BAE show the effects of international trade on global emissions. According to the sign of BEE and BAE of gross trade flows, these countries can be divided into four types. The first type is corresponding to positive BEE and BAE and promotes both domestic and global carbon emissions. China and Russia are the two representing countries, both of which have high carbon intensities and large trade surpluses. This means that products are produced in a country with comparative environmental disadvantages; therefore, both the BEE and BAE are positive, which is the least desirable condition. Liu et al. (2016b) find a positive balance of embodied emissions and a negative balance of avoided emissions of China with the rest of world. The different results of the manuscript and Liu et al.' study (2016b) can be explained from two perspectives. First, two papers adopt different methodology. Liu's study (2016b) adopts single-regional input-output (SRIO) model, and the manuscript adopts the multi-regional input-output (MRIO) model. The SRIO model has the transparency property, while the MRIO model is suitable to reflect the global production 
fragmentation, which is becoming more and more important. Second, Liu's study (2016b) focuses on greenhouse gas emissions, which includes carbon emission, methane emission, and so on. However, the manuscript only discusses carbon emissions.

The second type has negative BEE and positive BAE, and the representative country is the USA. The USA imports a large number of products from countries with relatively higher carbon intensities, such as China. For instance, Davis and Caldeira (2010) note the dominant carbon transfer is from China to the United States. The international trade contributes to emissions savings in the USA but results in a greater increase in carbon emission of the other developing countries. Therefore, the international trade of the United States would result in greater global emissions. The most desirable condition is that the international trade of a country, which belongs to the third type, contributes to a decrease in both domestic and global carbon emissions. The two representative countries are Germany and Japan, both of which have comparatively green technology and export oriented economies. The international trade of countries belonging to the fourth type promotes domestic direct emissions but generates global emissions savings, such as Taiwan. As noted by (Davis and Caldeira, 2010), Taiwan is a net exporter of embodied emissions. Therefore, international trade promotes the direct emissions of Taiwan. A large share of exported products of Taiwan are transferred to China that has a relatively larger carbon intensity. Thus, the international trade of Taiwan would reduce China's carbon emissions obviously and generates global emissions savings.

Countries specialize in different stages of international production and have different international trade structures and carbon intensities. This study further explains the environmental effect of each country's involvement in global value chains from the perspective of three different trade patterns. From the perspective of the trade in final products, China is still located corresponding to positive BEE and BAE, while Russia face negative BEE and BAE. This is because Russia imports a large quantity of final products from foreign countries with relatively low carbon intensities. It should be noted out that the trade in final products of India has the same characteristic as that of China, which contributes to an increase in both national direct and global emissions. This highlights that these two countries should pay special attention to the international final products trade. From the perspective of trade in intermediate 
products for the last stage of production, China is corresponding to positive BEE and negative BAE, which is consistent with the result of Liu et al.'s study (2016b). China imports large scale of intermediate products from other countries with lower carbon intensity for industrial production, the production of which generate less emissions than the condition that imported products are produced in China. In contrast to China, Russia exports a large volume of raw materials to foreign countries for further processing, which contributes to both national direct and global emissions. From the perspective of narrowly defined global value chain related trade pattern, Russia has a significant positive balance of avoided emissions, while many countries' positions in global value chains generate emissions savings, such as Korea, Taiwan, Japan and China. This is consistent with the above conclusion that global value chain related trade generates global emissions savings. However, the direct carbon emissions of developing countries such as China and Russia would increase for global production fragmentation, and developed countries such as Germany and Korea would generate a domestic carbon reduction. Briefly, there are significant differences in the environmental effects of different trade patterns for each country.

\section{Conclusions}

With the development of global value chains, global production fragmentation is reshaping the international trade pattern, and countries specialize in different stages of international production. This study splits the bilateral trade into three different trade patterns, parcels the pollution haven hypothesis into a multi-regional input-output analysis, and discusses the environmental effects of global production fragmentation. The main results and policy implications are summarized below.

This study disaggregates each country's direct emissions into the part associated with pure domestic economic activities and the part related to different trade patterns. We find that the share of emissions induced by international trade increased gradually and reached a peak in 2008. If we neglect the influence of the financial crisis in 1997 and 2008, the share of emissions embodied in global value chain related trade is increasing gradually, while the trade in intermediate products for the last stage of production still corresponds to the largest share of embodied emissions. A structural decomposition analysis shows that the carbon intensity change is a negative driver of the change in embodied emissions, while the change in trade scales tend to positively 
contribute to embodied emissions. Regional comparisons show that there are significant differences in the shares of different nations' emissions that are induced by different economic activities, which has a close relationship with each nation's portion in the global value chains.

This study extends the literature (Arce González et al., 2012; López et al., 2013a; López et al., 2013b; López et al., 2013c) and proposes a new method, which focuses on emissions that are induced by exports only through domestic economic linkage, to parcel the pollution haven hypothesis into the multi-regional input-output analysis. We find that the international trade corresponds to negative balances of avoided emissions over 1995-2009. In the absence of international trade, global carbon emissions would increase by 822.61 million tons in 2009, even though the international trade became less environmentally friendly after the shock of the economic crisis in 2008. The trade in final products became increasingly less environmentally effective for 1997-2009 because downstream production gradually shifted to developing countries with higher carbon intensities, such as China. From a bilateral perspective, the largest net carbon flow is from China to the USA through the trade in final products, which corresponds to a positive balance of avoided emissions. From national perspective, there are significant differences in the environmental effects of different trade patterns for each country.

The policy implication of this study is that global production fragmentation is reshaping the international trade pattern significantly, and the environmental provisions in the international trade agreement should not only focuses on the fast-developing trade in intermediate products but also be targeted at the traditional trade in final products, which has became less environmental effective. The environmental provisions should be based on the emissions generated in the full production process. For instance, border carbon adjustments (e.g. carbon tariffs on imports and rebates to exporters) should be targeted at the direct and indirect emissions generated in the production of traded products. In addition, the government should balance the economic development and environmental protection, during the process of improving a country's position in the global economy.

There are several potential extensions of this study that are worthy of pursuit. First, this study adopts "monetary data" to estimate the BAE, which may lead to some bias because the price difference among different countries (Liu et al., 2016b; Tukker et al., 
2013). Arto et al. (2014) recommend the physical approach. The future studies are expected to discuss how serious is how sensitive is the result to the price difference. Second, the domestic technology assumption adopted by this study assumes that imported products are produced with domestic technology assumption. However, the importers may not have the technology and natural resources to produce the imported products. The future related studies are expected to consider technology assumption and resource endowment (e.g., Duchin and López-Morales, 2012; Strømman et al., 2009). Third, there exist different multi-regional input-output databases for this study, such as WIOD, Eora, GTAP. These databases have different characters (please refer to Owen' study (2015)). It is suggested that future studies could apply the proposed method of this study to other databases and compare the calculation results.

\section{Acknowledgements}

The authors gratefully acknowledge the financial support from the National Science Foundation of China (Grant NOs. 71603179 and 71473245), the National Social Sciences Fund (Grant NO. 15AGL024), Fundamental Research Funds for the Central Universities in UIBE (CXTD7-06), and Tianjin Program of Philosophy and Social Science (TJGL16-007Q). We also would like to thank the anonymous referees as well as the editors.

\section{References}

Ackerman, F., Ishikawa, M., Suga, M., 2007. The carbon content of Japan-US trade. Energy Policy 35, 4455-4462.

Al-mulali, U., Tang, C.F., 2013. Investigating the validity of pollution haven hypothesis in the gulf cooperation council (GCC) countries. Energy Policy 60, 813-819.

Ang, B., Su, B., Wang, H., 2016. A spatial-temporal decomposition approach to performance assessment in energy and emissions. Energy Econ. 60, 112-121.

Ang, B.W., Liu, F., Chew, E.P., 2003. Perfect decomposition techniques in energy and environmental analysis. Energy Policy 31, 1561-1566.

Ang, B.W., Zhang, F., Choi, K.-H., 1998. Factorizing changes in energy and environmental indicators through decomposition. Energy 23, 489-495.

Arce González, G., Cadarso Vecina, M.A., López Santiago, L.A., Tobarra Gómez, M.A., Zafrilla Rodríguez, J.E., 2012. Indirect Pollution Haven Hypothesis in a context of Global Value Chain, Final WIOD Conference: Causes and Consequences of Globalization, Groningen, The Netherlands, April, 24th-26th, 2012. 
Arto, I., Roca, J., Serrano, M., 2014. Measuring emissions avoided by international trade: Accounting for price differences. Ecolog. Econ. 97, 93-100.

Borin, A., Mancini, M., 2015. Follow the value added: bilateral gross export accounting. Bank of Italy $\begin{array}{lllll}\text { Temi di Discussione } & \text { (Working }\end{array}$ https://www.bancaditalia.it/pubblicazioni/temi-discussione/2015/2015-1026/index.html?com.dotmar keting.htmlpage.language $=1$.

Chen, Z., Chen, G., 2011. Embodied carbon dioxide emission at supra-national scale: a coalition analysis for G7, BRIC, and the rest of the world. Energy Policy 39, 2899-2909.

Chung, H.-S., Rhee, H.-C., 2001. A residual-free decomposition of the sources of carbon dioxide emissions: a case of the Korean industries. Energy 26, 15-30.

Cole, M.A., Elliott, R.J., 2005. FDI and the capital intensity of "dirty" sectors: a missing piece of the pollution haven puzzle. Rev. Devel. Econ. 9, 530-548.

Conrad, K., 2005. Locational competition under environmental regulation when input prices and productivity differ. The Annals of Regional Science 39, 273-295.

Davis, S.J., Caldeira, K., 2010. Consumption-based accounting of CO2 emissions. Proceedings of the National Academy of Sciences 107, 5687-5692.

Dean, J.M., Lovely, M.E., 2010. Trade growth, production fragmentation, and China's environment. In: Feenstra R. Wei S (eds) China's growing role in world trade. University of Chicago Press, Chicago, 429-469.

Dietzenbacher, E., Los, B., 1998. Structural decomposition techniques: sense and sensitivity. Econ. Systems Res. 10, 307-324.

Dietzenbacher, E., Mukhopadhyay, K., 2007. An empirical examination of the pollution haven hypothesis for India: towards a green Leontief paradox? Environ. Resource Econ. 36, 427-449.

Dietzenbacher, E., Pei, J., Yang, C., 2012. Trade, production fragmentation, and China's carbon dioxide emissions. J. Environ. Econ. Manage. 64, 88-101.

Du, H., Guo, J., Mao, G., Smith, A.M., Wang, X., Wang, Y., 2011. CO 2 emissions embodied in China-US trade: Input-output analysis based on the emergy/dollar ratio. Energy Policy 39, 5980-5987.

Duchin, F., López-Morales, C., 2012. Do water-rich regions have a comparative advantage in food production? Improving the representation of water for agriculture in economic models. Econ. Systems Res. 24, 371-389.

Eskeland, G.S., Harrison, A.E., 2003. Moving to greener pastures? Multinationals and the pollution haven hypothesis. J. Devel. Econ. 70, 1-23.

Fan, Y., Xia, Y., 2012. Exploring energy consumption and demand in China. Energy 40, 23-30.

Gavrilova, O., Vilu, R., 2012. Production-based and consumption-based national greenhouse gas inventories: An implication for Estonia. Ecolog. Econ. 75, 161-173.

Guo, J., Zou, L.-L., Wei, Y.-M., 2010. Impact of inter-sectoral trade on national and global CO 2 emissions: an empirical analysis of China and US. Energy Policy 38, 1389-1397.

He, J., 2006. Pollution haven hypothesis and environmental impacts of foreign direct investment: the case of industrial emission of sulfur dioxide (SO 2) in Chinese provinces. Ecolog. Econ. 60, 228-245.

Hertwich, E., Peter, G., 2010. Multiregional Input-Output Database. One Planet Economy Network (OPEN) EU-Technical Document. http://www.oneplaneteconomynetwork.org/resources/programme-documents/WP1_MRIO_Technica I_Document.pdf.

Hoffmann, R., Lee, C.G., Ramasamy, B., Yeung, M., 2005. FDI and pollution: a granger causality test 
using panel data. J. Int. Devel. 17, 311-317.

Jiang, X., Guan, D., Zhang, J., Zhu, K., Green, C., 2015a. Firm ownership, China's export related emissions, and the responsibility issue. Energy Econ. 51, 466-474.

Jiang, X., Zhu, K., Green, C., 2015b. China's energy saving potential from the perspective of energy efficiency advantages of foreign-invested enterprises. Energy Econ. 49, 104-112.

Kander, A., Jiborn, M., Moran, D.D., Wiedmann, T.O., 2015. National greenhouse-gas accounting for effective climate policy on international trade. Nature Climate Change 5, 431-435.

Kheder, S.B., Zugravu, N., 2008. The pollution haven hypothesis: A geographic economy model in a comparative study. FEEM Working Paper No. 73.2008. http://dx.doi.org/10.2139/ssrn.1266705.

Koźluk, T., Timiliotis, C., 2016. Do environmental policies affect global value chains? a new perspective on the pollution haven hypothesis. OECD Economics Department Working papers, No. 1282, OECD Publishing, Pairs.

López, L.A., Arce, G., Kronenberg, T., 2013a. Pollution haven hypothesis in emissions embodied in world trade: The relevance of global value chains, The Wealth of Nations in a Globalizing World, Workshop EU FP7 WIOD Project, July, 18th-19th , 2013.

López, L.A., Arce, G., Zafrilla, J.E., 2013b. Financial crisis, virtual carbon in global value chains, and the importance of linkage effects. The Spain-China case. Environ. Sci. Technol. 48, 36-44.

López, L.A., Arce, G., Zafrilla, J.E., 2013c. Parcelling virtual carbon in the pollution haven hypothesis. Energy Econ. 39, 177-186.

Lenzen, M., Pade, L.-L., Munksgaard, J., 2004. CO2 multipliers in multi-region input-output models. Econ. Systems Res. 16, 391-412.

Leontief, W., 1941. The Structure of the American Economy 1919-1929: an empirical application of equilibrium analysis. Harvard University Press, Cambridge.

Levinson, A., Taylor, M.S., 2008. Unmasking the pollution haven effect. Int. Econ. Rev. 49, 223-254.

Liu, Z., Davis, S.J., Feng, K., Hubacek, K., Liang, S., Anadon, L.D., Chen, B., Liu, J., Yan, J., Guan, D., $2016 a$. Targeted opportunities to address the climate-trade dilemma in China. Nature Climate Change 6, 201-206.

Liu, Z., Song, P., Mao, X., 2016b. Accounting the effects of WTO accession on trade-embodied emissions: Evidence from China. Journal of Cleaner Production 139, 1383-1390.

Meng, B., Peters, G., Wang, Z., 2014. Tracing CO2 emissions in global value chains. Available at SSRN: http://dx.doi.org/10.2139/ssrn.2541893.

Owen, A.E., 2015. Techniques for evaluating the differences in consumption-based accounts: a comparative evaluation of Eora, GTAP and WIOD. Thesis.

Pei, J., Meng, B., Wang, F., Xue, J., 2015. Production sharing, demand spillovers and CO2 emissions: the case of Chinese regions in GVCs. IDE Discussion Papers. http://www.ide.go.jp/English/Publish/Download/Dp/493.html.

Peters, G.P., 2008. From production-based to consumption-based national emission inventories. Ecolog. Econ. 65, 13-23.

Peters, G.P., Andrew, R., Lennox, J., 2011. Constructing an environmentally-extended multi-regional input-output table using the GTAP database. Econ. Systems Res. 23, 131-152.

Peters, G.P., Weber, C.L., Guan, D., Hubacek, K., 2007. China's growing CO2 emissions a race between increasing consumption and efficiency gains. Environ. Sci. Technol. 41, 5939-5944.

Rezza, A.A., 2013. FDI and pollution havens: Evidence from the Norwegian manufacturing sector. Ecolog. Econ. 90, 140-149. 
Serrano, M., Dietzenbacher, E., 2010. Responsibility and trade emission balances: An evaluation of approaches. Ecolog. Econ. 69, 2224-2232.

Shui, B., Harriss, R.C., 2006. The role of CO 2 embodiment in US-China trade. Energy policy 34, 4063-4068.

Strømman, A.H., Hertwich, E.G., Duchin, F., 2009. Shifting trade patterns as a means of reducing global carbon dioxide emissions. Journal of Industrial Ecology 13, 38-57.

Su, B., Ang, B., 2011. Multi-region input-output analysis of CO 2 emissions embodied in trade: the feedback effects. Ecolog. Econ. 71, 42-53.

Su, B., Ang, B., 2012. Structural decomposition analysis applied to energy and emissions: some methodological developments. Energy Econ. 34, 177-188.

Su, B., Ang, B., 2014a. Attribution of changes in the generalized Fisher index with application to embodied emission studies. Energy 69, 778-786.

Su, B., Ang, B., 2014b. Input-output analysis of CO 2 emissions embodied in trade: a multi-region model for China. Applied Energy 114, 377-384.

Su, B., Ang, B., 2015. Multiplicative decomposition of aggregate carbon intensity change using input-output analysis. Applied Energy 154, 13-20.

Su, B., Ang, B., 2016. Multi-region comparisons of emission performance: The structural decomposition analysis approach. Ecol. Indicators 67, 78-87.

Su, B., Ang, B., Low, M., 2013. Input-output analysis of CO 2 emissions embodied in trade and the driving forces: processing and normal exports. Ecolog. Econ. 88, 119-125.

Su, B., Ang, B.W., 2013. Input-output analysis of CO2 emissions embodied in trade: Competitive versus non-competitive imports. Energy Policy 56, 83-87.

Su, B., Thomson, E., 2016. China's carbon emissions embodied in (normal and processing) exports and their driving forces, 2006-2012. Energy Econ. 59, 414-422.

Tan, H., Sun, A., Lau, H., 2013. CO 2 embodiment in China-Australia trade: The drivers and implications. Energy policy 61, 1212-1220.

Tang, J.P., 2015. Pollution havens and the trade in toxic chemicals: Evidence from US trade flows. Ecolog. Econ. 112, 150-160.

Taylor, M.S., 2005. Unbundling the pollution haven hypothesis. Advances in Economic Analysis \& Policy 3, 1-28.

Timmer, M.P., Dietzenbacher, E., Los, B., Stehrer, R., Vries, G.J., 2015. An illustrated user guide to the world input-output database: the case of global automotive production. Rev. Int. Econ. 23, 575-605.

Tukker, A., de Koning, A., Wood, R., Moll, S., Bouwmeester, M.C., 2013. Price corrected domestic technology assumption-a method to assess pollution embodied in trade using primary official statistics only. with a case on $\mathrm{CO} 2$ emissions embodied in imports to europe. Environ. Sci. Technol. 47, 1775-1783.

Usubiaga, A., Acosta-Fernández, J., 2015. Carbon emission accounting in MRIO models: the territory vs. the residence principle. Econ. Systems Res. 27, 458-477.

Walter, I., Ugelow, J.L., 1979. Environmental policies in developing countries. Ambio, 102-109.

Wang, Z., Wei, S.-J., Yu, X., Zhu, K., 2017. Characterizing Global and Regional Manufacturing Value Chains: Stable and Evolving Features. Working Papers. http//dagliano.unimi.it/wp-content/uploads/2017/01/WP2017_419.pdf.

Wang, Z., Wei, S., Zhu, K., 2013. Quantifying international production sharing at the bilateral and sector levels. Working papers. http://www.nber.org/papers/w19677. 
Wiedmann, T., Wood, R., Minx, J.C., Lenzen, M., Guan, D., Harris, R., 2010. A carbon footprint time series of the UK-results from a multi-region input-output model. Econ. Systems Res. 22, 19-42.

Xia, Y., Fan, Y., Yang, C., 2015. Assessing the impact of foreign content in China's exports on the carbon outsourcing hypothesis. Applied Energy 150, 296-307.

$\mathrm{Xu}, \mathrm{Y}$. , Dietzenbacher, E., 2014. A structural decomposition analysis of the emissions embodied in trade. Ecolog. Econ. 101, 10-20.

Zhang, Y.G., 2015. China's Regional Trade Patterns under the Perspective of Carbon Emissions:Pollution Haven and Factor Endowment. China Industrial Economics, 5-19.

Zhang, Z., Guo, J.e., Hewings, G.J., 2014. The effects of direct trade within China on regional and national CO 2 emissions. Energy Econ. 46, 161-175.

Zhao, Y., Wang, S., Zhang, Z., Liu, Y., Ahmad, A., 2016. Driving factors of carbon emissions embodied in China-US trade: a structural decomposition analysis. Journal of Cleaner Production 131, 678-689. 
Appendix A. the 40 countries in the WIOD database

\begin{tabular}{clclcl}
\hline Code & Countries & Code & Countries & Code & Countries \\
\hline 1 & Australia & 15 & France & 29 & Malta \\
2 & Austria & 16 & United Kingdom & 30 & Netherlands \\
3 & Belgium & 17 & Greece & 31 & Poland \\
4 & Bulgaria & 18 & Hungary & 32 & Portugal \\
5 & Brazil & 19 & Indonesia & 33 & Romania \\
6 & Canada & 20 & India & 34 & Russia \\
7 & China & 21 & Ireland & 35 & Slovak Republic \\
8 & Cyprus & 22 & Italy & 36 & Slovenia \\
9 & Czech Republic & 23 & Japan & 37 & Sweden \\
10 & Germany & 24 & Korea & 38 & Turkey \\
11 & Denmark & 25 & Lithuania & 39 & Taiwan \\
12 & Spain & 26 & Luxembourg & 40 & United states \\
13 & Estonia & 27 & Latvia & 41 & Rest of world \\
14 & Finland & 28 & Mexico & & \\
\hline
\end{tabular}

\section{Appendix B. the 35 sectors in the WIOD database}

\begin{tabular}{ll}
\hline Index & Sectors \\
\hline c1 & Agriculture, Hunting, Forestry and Fishing \\
c2 & Mining and Quarrying \\
c3 & Food, Beverages and Tobacco \\
c4 & Textiles and Textile Products \\
c5 & Leather, Leather and Footwear \\
c6 & Wood and Products of Wood and Cork \\
c7 & Pulp, Paper, Paper, Printing and Publishing \\
c8 & Coke, Refined Petroleum and Nuclear Fuel \\
c9 & Chemicals and Chemical Products \\
c10 & Rubber and Plastics \\
c11 & Other Non-Metallic Mineral \\
c12 & Basic Metals and Fabricated Metal \\
c13 & Machinery, Nec \\
c14 & Electrical and Optical Equipment \\
c15 & Transport Equipment \\
c16 & Manufacturing, Nec; Recycling \\
c17 & Electricity, Gas and Water Supply \\
c18 & Construction \\
c19 & Sale, Maintenance and Repair of Motor Vehicles and Motorcycles; Retail Sale of Fuel \\
c20 & Wholesale Trade and Commission Trade, Except of Motor Vehicles and Motorcycles \\
c21 & Retail Trade, Except of Motor Vehicles and Motorcycles; Repair of Household Goods \\
c22 & Hotels and Restaurants \\
\hline
\end{tabular}




\begin{tabular}{ll}
\hline Index & Sectors \\
\hline c23 & Inland Transport \\
c24 & Water Transport \\
c25 & Air Transport \\
c26 & Other Supporting and Auxiliary Transport Activities; Activities of Travel Agencies \\
c27 & Post and Telecommunications \\
c28 & Financial Intermediation \\
c29 & Real Estate Activities \\
c30 & Renting of M\&Eq and Other Business Activities \\
c31 & Public Admin and Defence; Compulsory Social Security \\
c32 & Education \\
c33 & Health and Social Work \\
c34 & Other Community, Social and Personal Services \\
c35 & Private Households with Employed Persons \\
\hline
\end{tabular}

\section{Appendix C. The LMDI formula for each effect}

\begin{tabular}{|c|c|}
\hline & Mathematical expressions \\
\hline$\Delta E E X_{F}^{s r}$ & $\sum_{i, j, p} \frac{F_{i i, t l}^{s} L_{i j, t l}^{s s} T_{j, p, t l}^{s r}-F_{i i, t 0}^{s} L_{i j, t 0}^{s s} T_{j, p, t 0}^{s r}}{\ln \left(F_{i i, t l}^{s} L_{i j, t l}^{s} T_{j, p, t l}^{s r}\right)-\ln \left(F_{i i, t 0}^{s} L_{i j, t 0}^{s s} T_{j, p, t 0}^{s r}\right)} \ln \left(\frac{F_{i i, t l}^{s}}{F_{i i, t 0}^{s}}\right)$ \\
\hline$\Delta E E X_{L}^{s r}$ & $\sum_{i, j, p} \frac{F_{i i, t l}^{s} L_{i j, t l}^{s s} T_{j, p, t l}^{s r}-F_{i i, t 0}^{s} L_{i j, t 0}^{s s} T_{j, p, t 0}^{s r}}{\ln \left(F_{i i, t l}^{s} L_{i j, t l}^{s s} T_{j, p, t l}^{s r}\right)-\ln \left(F_{i i, t 0}^{s} L_{i j, t 0}^{s s} T_{j, p, t 0}^{s r}\right)} \ln \left(\frac{L_{i j, t l}^{s s}}{L_{i j, t 0}^{s s}}\right)$ \\
\hline$\Delta E E X_{T_{-} f}^{s r}$ & $\sum_{i, j} \frac{F_{i i, t l}^{s} L_{i j, t l}^{s s} T_{-} f_{j, t l}^{s r}-F_{i i, t}^{s} L_{i j, t 0}^{s s} T_{-} f_{j, t 0}^{s r}}{\ln \left(F_{i i, t l}^{s} L_{i j, t l}^{s s} T_{-} f_{j, t l}^{s r}\right)-\ln \left(F_{i i, t 0}^{s} L_{i j, t 0}^{s s} T_{-} f_{j, t 0}^{s r}\right)} \ln \left(\frac{T_{-} f_{j, t l}^{s r}}{T_{-} f_{j, t 0}^{s r}}\right)$ \\
\hline$\Delta E E X_{T_{-} i}^{s r}$ & $\sum_{i, j} \frac{F_{i i, t l}^{s} L_{i j, t l}^{s s} T_{-} i_{j, t l}^{s r}-F_{i i, t 0}^{s} L_{i j, t 0}^{s s} T_{-} i_{j, t 0}^{s r}}{\ln \left(F_{i i, t l}^{s} L_{i j, t l}^{s s} T_{-} i_{j, t l}^{s r}\right)-\ln \left(F_{i i, t 0}^{s} L_{i j, t 0}^{s s} T_{-} i_{j, t 0}^{s r}\right)} \ln \left(\frac{T_{-} i_{j, t l}^{s r}}{T_{-} i_{j, t 0}^{s r}}\right)$ \\
\hline$\Delta E E X_{T_{-} g}^{s r}$ & $\sum_{i, j} \frac{F_{i i, t l}^{s} L_{i j, t l}^{s s} T_{-} g_{j, t l}^{s r}-F_{i i, t 0}^{s} L_{i j, t 0}^{s s} T_{-} g_{j, t 0}^{s r}}{\ln \left(F_{i i, t l}^{s} L_{i j, t l}^{s s} T_{-} g_{j, t l}^{s r}\right)-\ln \left(F_{i i, t 0}^{s} L_{i j, t 0}^{s s} T_{-} g_{j, t 0}^{s r}\right)} \ln \left(\frac{T_{-} g_{j, t l}^{s r}}{T_{-} g_{j, t 0}^{s r}}\right)$ \\
\hline
\end{tabular}

Notes: $p$ represents different trade patterns. 


\section{Colour Figures}

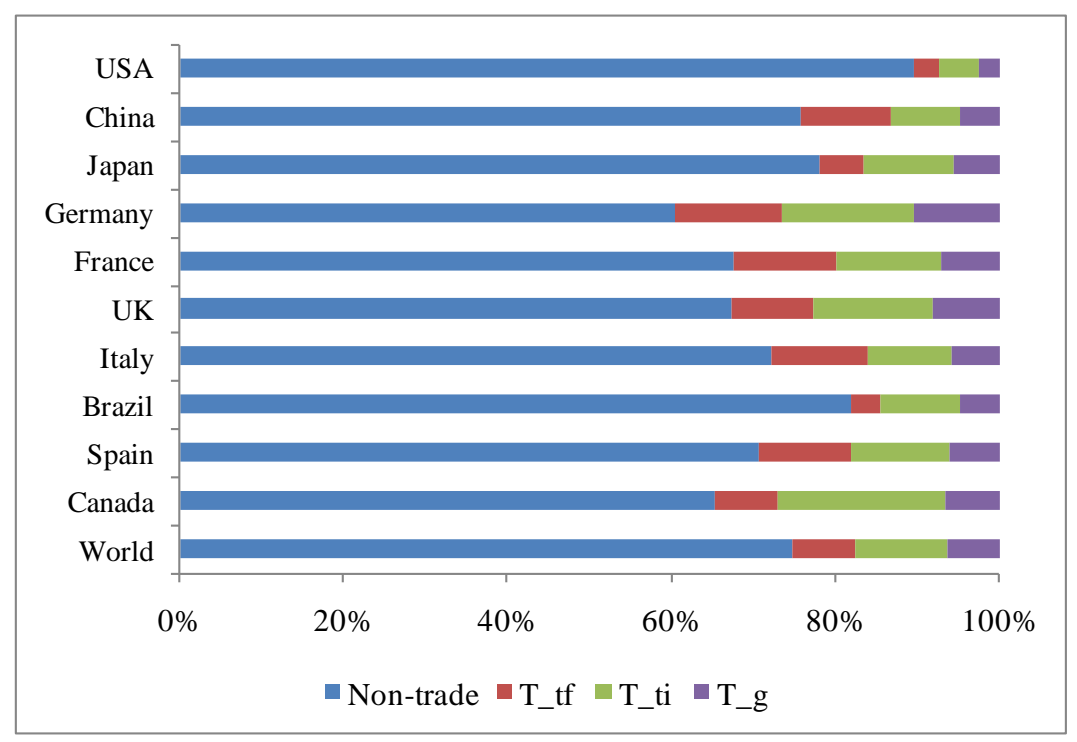

Notes: Non-trade: pure domestic economic activities; T_f: trade in final products; $\mathrm{T}$ _i: trade in intermediate products for the last stage of production; $\mathrm{T} \_\mathrm{g}$ : narrowly defined global value chain related trade.

Figure 2. Decomposition of direct emissions of the top ten economic agents and the global emissions in 2009

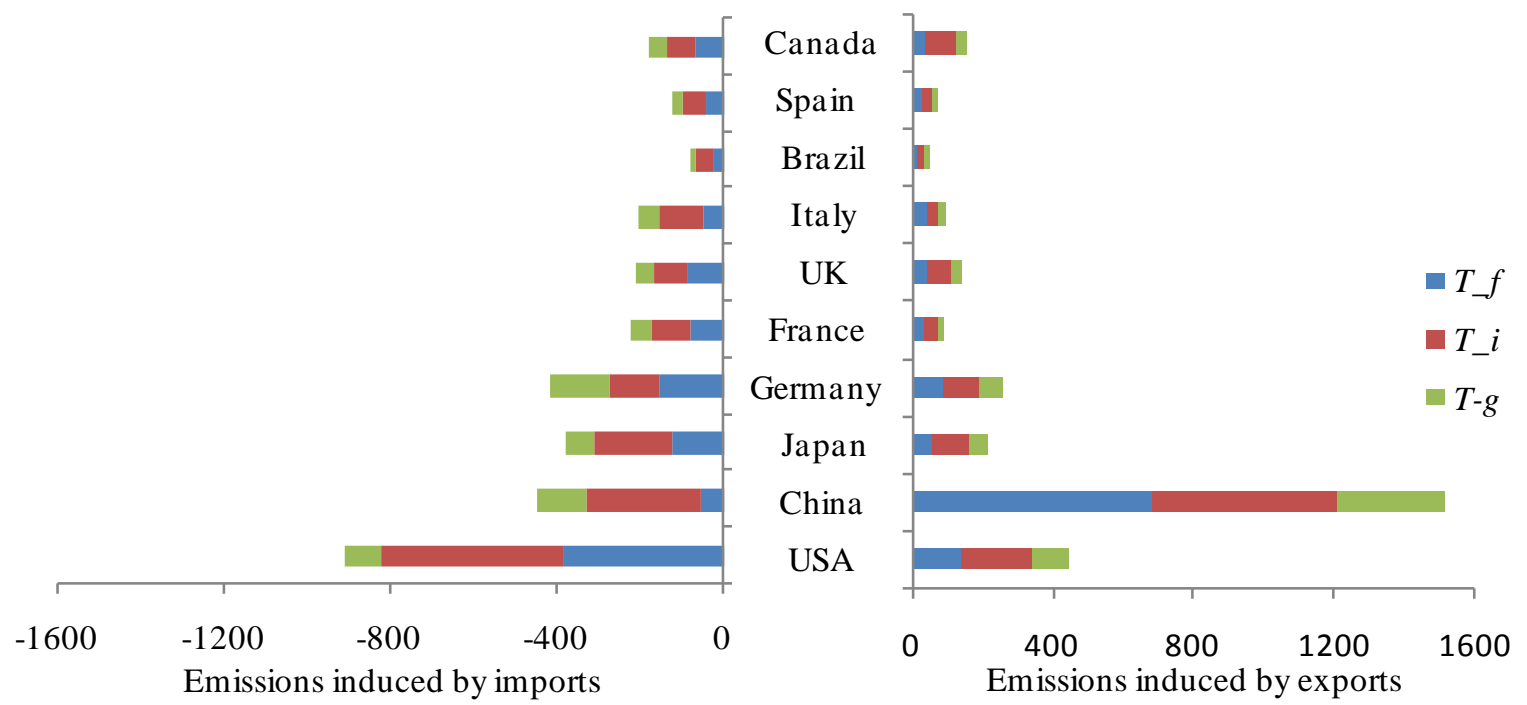

Figure 3. Emissions induced by trade of the top ten economy agents in 2009 (million tons) 


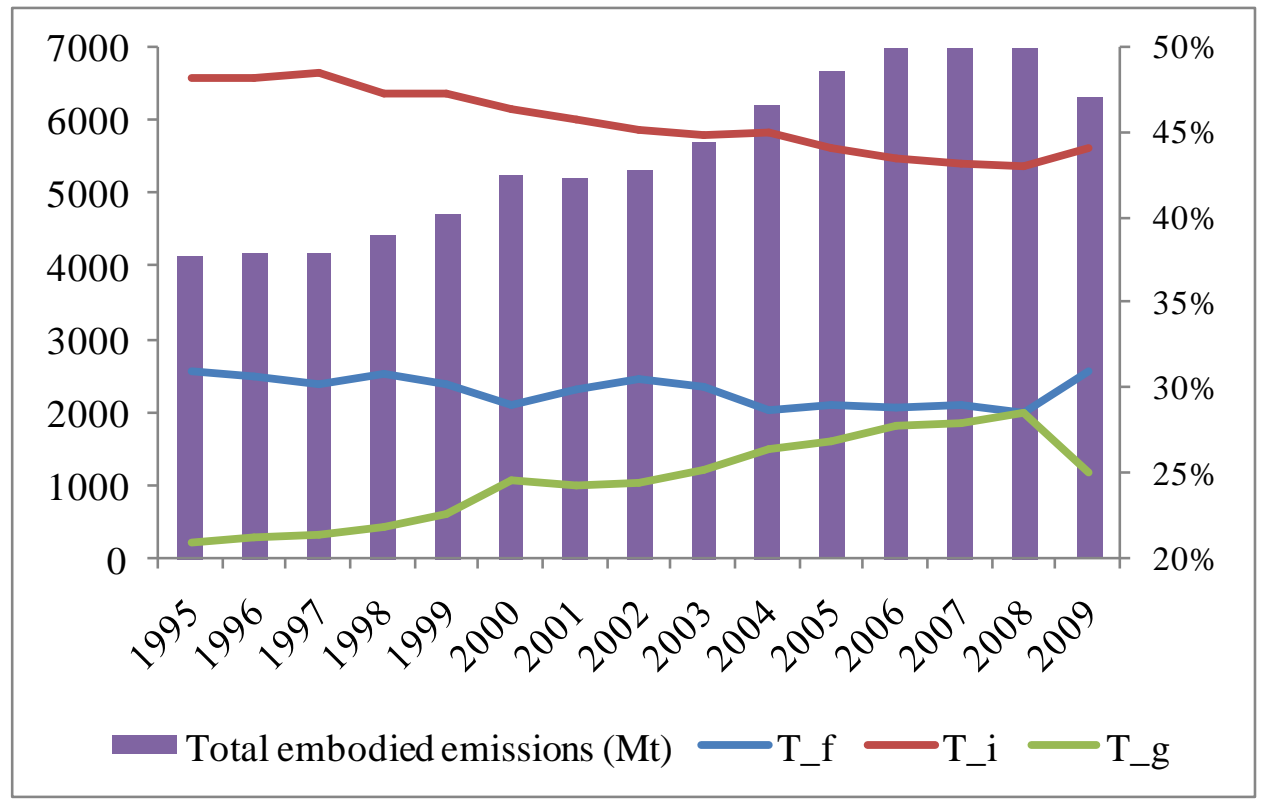

Figure 4. The structure of emissions induced by international trade

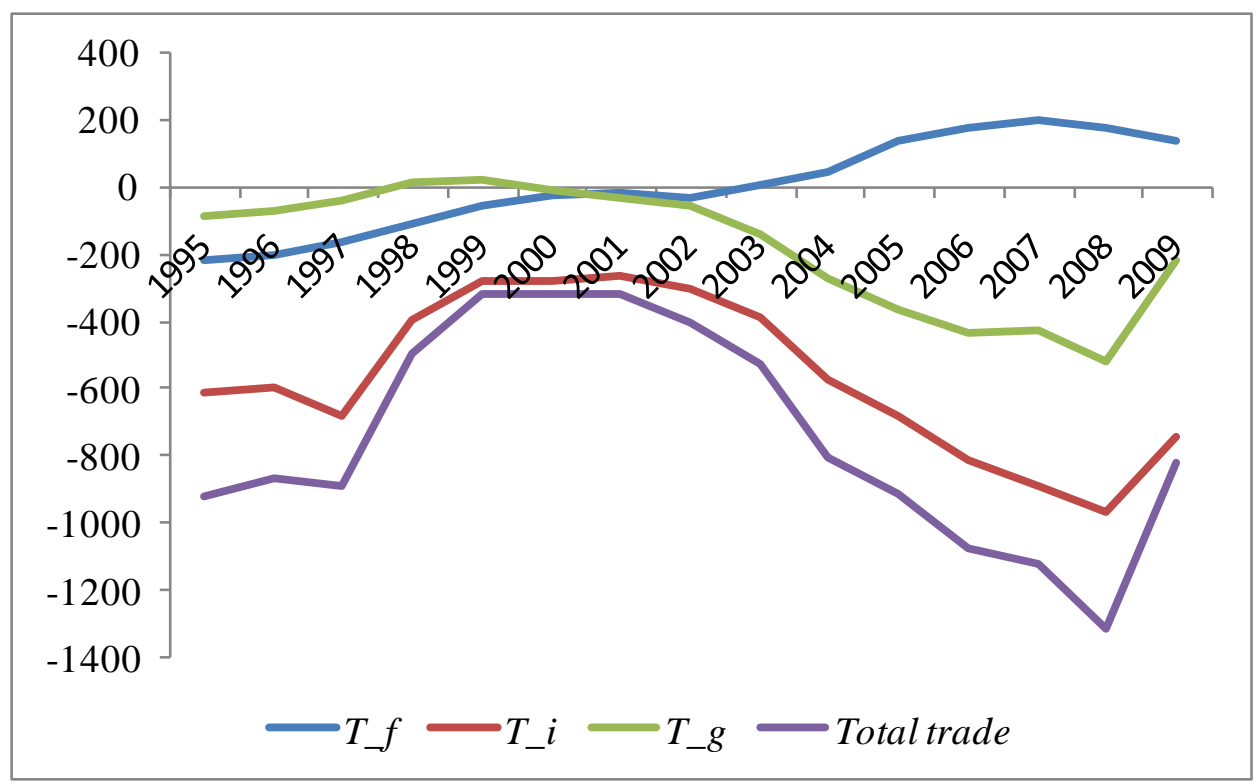

Figure 5. The effects of three different trade patterns on global emissions (million tons) 